This document is the accepted manuscript version of the following article:

Shi, Z., Geng, G., Leemann, A., \& Lothenbach, B. (2019). Synthesis, characterization, and water uptake property of alkali-silica reaction products. Cement and Concrete Research, 121, 58-71. https://doi.org/10.1016/j.cemconres.2019.04.009

This manuscript version is made available under the CC-BY-NC-ND 4.0

license http://creativecommons.org/1icenses/by-nc-nd/4.0/

\title{
Synthesis, characterization, and water uptake property of alkali-silica reaction products
}

\author{
Zhenguo Shi $^{\mathrm{a}^{*}}$, Guoqing Geng ${ }^{\mathrm{b}}$, Andreas Leemann ${ }^{\mathrm{a}}$, Barbara Lothenbach ${ }^{\mathrm{a}, \mathrm{c}}$
}

${ }^{a}$ Laboratory for Concrete \& Construction Chemistry, Swiss Federal Laboratories for Materials Science and Technology (Empa), 8600 Dübendorf, Switzerland

b Laboratory for Waste Management, Paul Scherrer Institut, 5232 Villigen PSI, Switzerland

${ }^{c}$ Department of Structural Engineering, Norwegian University of Science and Technology (NTNU), 7491 Trondheim, Norway

* Corresponding author. Laboratory for Concrete \& Construction Chemistry, Swiss Federal Laboratories for Materials Science and Technology (Empa), 8600 Dübendorf, Switzerland. E-mail address: zhenguo.shi@empa.ch (Z. Shi). 


\begin{abstract}
:
The reaction mechanism of alkali-silica reaction (ASR) is poorly understood due to the difficulties to directly characterize ASR products in concrete. In this study, ASR products with initial $\mathrm{Ca} / \mathrm{Si}$ of 0.25 and $(\mathrm{K}+\mathrm{Na}) / \mathrm{Si}$ ratio 0.5 with different $\mathrm{K} / \mathrm{Na}$ ratios are synthesized at $80{ }^{\circ} \mathrm{C}$. The synthesized ASR products are characterized by different techniques, also the solution chemistry is analyzed and saturation indices are calculated. The results show that crystalline and nano-crystalline phases are formed in the presence of both alkalis and calcium. No ASR product is present in the absence of calcium. All synthesized crystalline ASR products highly resembles the crystal structure of shlykovite, indicating that a substitution of $\mathrm{K}$ in shlykovite by $\mathrm{Na}$ can occur. Its silicate sheet structure has strong similarity to the ASR products formed in concrete according to Raman spectra, while some differences are observed in their morphologies and basal peak of the XRD patterns.
\end{abstract}

Keywords: alkali-silica reaction; shlykovite; C-S-H; pH; saturation index 


\section{Introduction}

Alkali-silica reaction (ASR) causes expansion and cracking of concrete due to the reaction of reactive silica from aggregates with hydroxide ions from the pore solution of concrete in presence of alkalis $\left(\mathrm{Na}^{+}\right.$and/or $\left.\mathrm{K}^{+}\right)$and calcium. Since ASR was first described by Stanton in 1940's [1], a large number of concrete structures such as bridges, dams and pavements have been affected by ASR leading to substantial costs for repair and replacement. Over the past 80 years, ASR has been extensively investigated [2][3][4][5][6][7]. Scanning Electron Microscopy coupled with Energy Dispersive X-ray Spectroscopy (SEM/EDX) has shown that ASR products formed in aggregates predominantly consists of silicon, alkalis and calcium with characteristic atomic ratios of $(\mathrm{Na}+\mathrm{K}) / \mathrm{Si} \approx 0.25$ and $\mathrm{Ca} / \mathrm{Si} \approx 0.25$ [8][9][10][11]. Measures to mitigate ASR expansion including the use of supplementary cementitious materials [4][3] or lithium salts [12][13] have been successfully developed. However, much of the knowledge obtained so far about ASR and possible mitigation strategies is based on empirical approaches, as the mineralogy and structure of ASR products, and the precise mechanisms of the reaction remain poorly understood. Therefore, predictions of the occurrence and kinetics of the ASR and the resulting expansion of concrete are still difficult.

The main challenge limiting the understanding of the fundamentals of ASR is the insufficient characterization of ASR products, as ASR products are usually formed in tiny amounts with very small size ( $\mu \mathrm{m}$ range) co-existing with other silica-rich phases in concrete [11]. This makes it difficult to characterize them using conventional techniques such as solid-state ${ }^{29} \mathrm{Si}$ magic-angle spinning Nuclear Magnetic Resonance ( ${ }^{29} \mathrm{Si}$ MAS NMR), thermogravimetric analysis (TGA) or X-ray diffraction analysis (XRD). The bulk characterizations of the ASR products using these techniques as reported in literature are mainly based on reaction products extruded or present in air voids [14][15]. However, the structure of these ASR products can be altered by the uptake of additional $\mathrm{Ca}$ from the surrounding cement paste leading to the formation of a low $\mathrm{Ca} / \mathrm{Si}$ ratio calcium-silicate-hydrate (C-S-H) as shown in [8]. As these products are not the same as the ones present in the aggregates, this situation may lead to misunderstanding about the ASR 
products formed in concrete aggregates where the stress leading to concrete damage is generated. Several studies have also described the crystal structure of ASR products based on kanemite [16], okenite [17] mountainite and rhodesite [18]. Recent advances in synchrotron-based micro XRD allowed to directly study the ASR products with a size of 15 $40 \mu \mathrm{m}$ formed within aggregates [19]. The results revealed that the ASR product consisted of a sheet silicate which showed some similarity to mountainite and rhodesite. Crystalline and amorphous ASR products could also be directly analyzed within the aggregate using micro-Raman spectroscopy [20], which showed that the silicate species of ASR products are dominated by $\mathrm{Q}^{3}$ sites indicating again layers of silica tetrahedra sharing three bridging oxygens. However, more work needs to be conducted along these tracks to provide full structure information of the ASR products.

An alternative approach which allows the characterization of the ASR products using wider range of techniques is to synthesize larger amount of ASR products in laboratory. This approach has been attempted in several studies [21][22][23][24]. Overall, the synthesized products from these studies also show presence of $\mathrm{Q}^{3}$ polymerization, which suggests the formation of layered silicate sheet structure of ASR products, consistent with the observation from synchrotron-based micro XRD and Raman spectroscopy on field samples [19][20]. However, these synthesized ASR products contained usually mainly C-S-H or unreacted silica as a result of the following factors: (i) low reactivity of the silica used, (ii) overestimation of the amount of $\mathrm{Ca}(\mathrm{OH})_{2}$ for the starting mixtures with the idea to assure a constant reservoir of $\mathrm{Ca}$ as in actual hydrated cement or concrete, and (iii) low reaction temperature and short reaction period. Nevertheless, the observation of layered silicate species within the synthesized reaction products suggests that it is possible to synthesize ASR products under laboratory conditions.

In this study, syntheses of different ASR products are attempted by mixing freshly burnt $\mathrm{CaO}$ and highly reactive amorphous silica with alkali solution at target $\mathrm{Ca} / \mathrm{Si}$ and $(\mathrm{Na}+\mathrm{K}) / \mathrm{Si}$ ratios similar to those observed under field conditions and with varying $\mathrm{K} / \mathrm{Na}$ ratios at $80^{\circ} \mathrm{C}$. The obtained products are characterized by several different techniques such as XRD, ${ }^{29} \mathrm{Si}$ 
MAS NMR, Raman spectra, Fourier Transformation-Infrared (FTIR) spectra, thermogravimetric analysis (TGA/DTA), dynamic vapor sorption (DVS), and SEM. The chemical compositions of the solutions are also analyzed using ionic chromatography (IC). The saturation index of the solution with respect to amorphous silica and C-S-H are calculated based on the measured concentrations of the solutions. The information obtained for the synthesized ASR products are expected to add fundamental knowledge to the structures and potential formation mechanism of the ASR products formed in concrete and to develop thermodynamic data for the ASR products.

\section{Materials and methods}

\subsection{Sample preparation}

The alkali-silica reaction products were synthesized by mixing amorphous silica (hydrophilic silica $\left(\mathrm{SiO}_{2}\right)$, surface area $200 \mathrm{~m}^{2} / \mathrm{g}$, from EVONIK industries) with freshly burnt $\mathrm{CaO}$ (obtained by burning calcium carbonate for $12 \mathrm{~h}$ at $1000{ }^{\circ} \mathrm{C}$ ) and $\mathrm{NaOH}$ and/or $\mathrm{KOH}$ pellet at designated portions. Samples with different $\mathrm{K} / \mathrm{Na}$ ratios $(0,1.0,2.3$ and 6.1) and $\mathrm{Na} / \mathrm{K}$ ratio of 0 were prepared with a constant $(\mathrm{K}+\mathrm{Na}) / \mathrm{Si}$ ratio of 0.5 and $\mathrm{Ca} / \mathrm{Si}$ ratio of 0.25 as shown in Table 1 , which is also illustrated in Fig. 1 with the initial chemical compositions projected in both $\mathrm{CaO}-\mathrm{M}_{2} \mathrm{O}-\mathrm{SiO}_{2}$ and $\mathrm{CaO}-\mathrm{Na}_{2} \mathrm{O}-\mathrm{K}_{2} \mathrm{O}$ ternary diagrams. To distinguish the $\mathrm{K} / \mathrm{Na}$ ratios, these samples are noted as $\mathrm{SNC}, \mathrm{SK}_{0.25} \mathrm{~N}_{0.25} \mathrm{C}, \mathrm{SK}_{0.35} \mathrm{~N}_{0.15} \mathrm{C}$, $\mathrm{SK}_{0.43} \mathrm{~N}_{0.07} \mathrm{C}$ and SKC. SKC\# is a replicate synthesis of SKC, the difference is that SKC\# was shaken weekly during synthesis. Different $\mathrm{K} / \mathrm{Na}$ ratios were chosen since concrete mixtures produced with cements having a similar $\mathrm{Na}_{2} \mathrm{O}$-equivalent but different $\mathrm{K} / \mathrm{Na}$-ratios can have considerably different expansion [25]. A reference sample, C-S-H_Na, with relatively higher $\mathrm{Ca} / \mathrm{Si}$ of 0.3 and lower $\mathrm{Na} / \mathrm{Si}$ ratio of 0.25 was prepared. Two additional reference samples (labeled Na-gel and K-gel) were prepared in the absence of $\mathrm{Ca}$ with $\mathrm{Na}(\mathrm{K}) / \mathrm{Si}$ ratio of 0.5 . The water/solid (w/s) mass ratio was around 5 for synthesis of the ASR products. The slight adjustment of the water content was to ensure that these samples having the same initial alkali $(\mathrm{K}+\mathrm{Na})$ concentration of $1 \mathrm{~mol} / \mathrm{L}$. Higher w/s ratios (i.e., 17.3, 10.2, 11.3) were applied 
to the three reference samples to lower the initial solution alkalinity. All samples were prepared in Teflon bottles in a $\mathrm{N}_{2}$ filled glove box to minimize $\mathrm{CO}_{2}$ contamination, and then placed in incubator at $80{ }^{\circ} \mathrm{C}$ for reaction for 80 days. Afterwards, roughly $5 \mathrm{~mL}$ solution of each sample was obtained by filtration of the sample with $20 \mu \mathrm{m}$ paper filter. The obtained solution for each sample was then filtered with $0.45 \mu \mathrm{m}$ syringe filter for $\mathrm{pH}$ measurement and solution composition analysis. After filtration, the solids were rinsed first with approximately $50 \mathrm{~mL}$ of 1:1 water-ethanol solution and then with $50 \mathrm{~mL} 94 \%$ ethanol solution in the $\mathrm{N}_{2}$ filled glove box. The solids were vacuum dried for seven days, and then stored in $\mathrm{N}_{2}$ filled desiccators with $\mathrm{CO}_{2}$ absorbent to prevent carbonation.

The field samples were obtained from an ASR affected bridge built in 1969. More information on the structure, the concrete and the cores taken is given in [10]. Only ASR products present within aggregates were used for analysis.

\subsection{Solid phase analysis}

The phases in the solids were determined by a conventional X-ray powder diffraction (XRD, PANalytical X'pert Pro) with $\mathrm{CoK} \alpha$ radiation in a $\theta-\theta$ configuration. The samples were scanned with a step size of $0.017^{\circ} 2 \theta$ between 5 and $90^{\circ} 2 \theta$ with the $\mathrm{X}^{\prime}$ Celerator detector during $150 \mathrm{~min}$. In addition to the conventional XRD measurement, the XRD of SKC\# was also measured in beamline 6-ID-D in Advanced Photon Source to further analyze the structural similarity and difference between the synthesized crystalline ASR product with its natural analog. The SKC\# powder was packed in a $1.5 \mathrm{~mm}$ Kapton capillary tube and placed between the upstream and an image plate detector. The incident beam energy is $\sim 100 \mathrm{keV}$. The sample position was calibrated via measuring a $\mathrm{CeO}_{2}$ standard, which was later used to calibrate the instrument line broadening effect. The data was analyzed using the MAUD package [26]. Similar structural analysis was also performed on the SNC sample however based on conventional XRD data. The sample geometries for the different XRD experiments were taken into account in the MAUD package, so that the angle-dependences of the diffraction intensity were properly accounted during the refinement. 
The ${ }^{29} \mathrm{Si}$ MAS NMR experiments were recorded on a Bruker Avance III NMR spectrometer using a $7 \mathrm{~mm} \mathrm{CP/MAS}$ probe at $79.5 \mathrm{MHz}$ applying the following parameters: $4500 \mathrm{~Hz}$ sample rotation rate, minimum of 10240 scans or more, $30^{\circ}{ }^{1} \mathrm{H}$ pulse of $2.5 \mu \mathrm{s}, 20 \mathrm{~s}$ relaxation delays, RF field strength of $33.3 \mathrm{kHz}$ during SPINAL64 proton decoupling. The ${ }^{29} \mathrm{Si}$ chemical shifts NMR spectra were externally referenced to tetramethylsilane (TMS) at $0.0 \mathrm{ppm}$.

Raman spectra and Fourier Transformation-Infrared (FTIR) spectra were recorded on the powdered samples. In case of the bridge, Raman microscopy was conducted on grinded concrete samples as described in more detail in [20]. Raman spectra were measured with a Bruker Senterra instrument equipped with a Peltier-cooled CCD detector and operated with the software Opus 6.5. The wave length of the used laser was $532 \mathrm{~nm}$ operated at $20 \mathrm{~mW}$. Length magnification was $50 \mathrm{x}$. The spectral acquisition time was $20 \mathrm{~s}$ and spectrum resolution in the used frequency range of $110 \sim 1560 \mathrm{~cm}^{-1}$ was $3-5 \mathrm{~cm}^{-1}$. About 10-20 spectra were collected per sample. The spectra were background corrected and normalized. FTIR spectra were recorded on a Bruker Tensor 27 FT-IR spectrometer by transmittance between 600 and $4000 \mathrm{~cm}^{-1}$ with a resolution of $4 \mathrm{~cm}^{-1}$ on $\sim 3 \mathrm{mg}$ of powder.

Thermogravimetric analysis (TGA/DTA) and dynamic vapor sorption (DVS) were applied to study the water behavior of the studied samples. TGA/DTA was done with a Mettler Toledo TGA/SDTA 8513 on 10 to $30 \mathrm{mg}$ samples using a heating rate of $20{ }^{\circ} \mathrm{C} / \mathrm{min}$ from 30 to $980^{\circ} \mathrm{C}$. DVS was performed on approximately $0.3 \mathrm{~g}$ samples. At the beginning, the sample was equilibrated at $\mathrm{RH}$ of $35 \%$. Afterwards, the sample was subjected to a stepwise absorption and then desorption process. Each $\mathrm{RH}$ step was maintained until moisture equilibrium was reached with a mass change of $0.002 \%$ per five minutes.

Secondary electron images of the carbon coated samples were collected using a scanning electron microscope (SEM) FEI Quanta 650 with an Everhart Thornley Detector. An acceleration voltage of $2-10 \mathrm{kV}$, a spot size 2 or 3 and a pressure of $3.0-5.0 \times 10^{-6}$ Torr were used. 


\subsection{Solution analysis and chemical composition of the obtained solids}

The $\mathrm{pH}$ measurements were carried out immediately after filtration using small fraction of the filtrated solution at room temperature around $23{ }^{\circ} \mathrm{C}$ with a Knick pH meter $(\mathrm{pH}-\mathrm{Meter}$ 766) equipped with a Knick SE100 electrode. Another part of filtrated solution was diluted in ratios of 1:10, 1:100 and 1:1000 with MilliQ water immediately after filtration and used for ionic chromatography (IC) analysis. The chemical composition of the obtained solids is calculated by mass balance based on the chemical composition of the starting materials and the chemical composition of the solution at equilibrium, assuming no significant change of volume of the aqueous phase throughout the reaction.

\subsection{Calculation of saturation indices}

Saturation indices with respect to amorphous silica and C-S-H were calculated based on the measured compositions of the solutions using the Gibbs free energy minimization program, GEMS v3.3 [27][28] together with the PSI/Nagra general thermodynamic database [29] and the Cemdata18 database [30] using the CSHQ model for C-S-H [31].

\section{Results and discussion}

\subsection{Chemical compositions of the solids}

The bulk chemical compositions of the solids obtained after filtration are calculated from mass balance and projected in both $\mathrm{CaO}-\mathrm{SiO}_{2}-\mathrm{M}_{2} \mathrm{O}$ and $\mathrm{CaO}-\mathrm{K}_{2} \mathrm{O}-\mathrm{Na}_{2} \mathrm{O}$ ternary diagrams as shown in Table 2 and in Fig. 2 together with the projection of the starting material proportions used for the synthesis. The results show a shift of the alkali contents to lower values as compared to the starting alkali contents, while an increase of Ca content in the solids is observed for all samples containing $\mathrm{CaO}$ in the starting materials. The lowering of $(\mathrm{Na}+\mathrm{K}) / \mathrm{Si}$ ratios is expected as the starting ratios except for sample C-S-H_Na are two times higher than the target ratio of 0.25 for the ASR products. The chemical compositions of the ASR products formed in concrete [10] are also plotted in Fig. 2 for comparison. Overall, the 
$\mathrm{Ca} / \mathrm{Si}$ and $(\mathrm{Na}+\mathrm{K}) / \mathrm{Si}$ ratios of the synthesized ASR products are similar to those of ASR products formed in concrete in particular for samples with high $\mathrm{K} / \mathrm{Na}$ ratios.

\subsection{Phase identification by conventional XRD}

The powder X-ray diffraction (XRD) patterns for the solids obtained after 80 days of reaction at $80^{\circ} \mathrm{C}$ are shown in Fig. 3. For the two reference samples (K-gel and Na-gel) in the absence of $\mathrm{Ca}$, the major phase identified is amorphous silica as reflected by the hump observed at $26^{\circ} 2 \theta$. A minor amount of a crystalline phase is observed in the Na-gel sample, which is attributed to the formation of natrite $\left(\mathrm{Na}_{2} \mathrm{CO}_{3}, \mathrm{PDF} \#\right.$ 98-006-8104). No crystalline alkali-silicate hydrates such as e.g. kanemite $\left(\mathrm{NaHSiO}_{2} \mathrm{O}_{5} \cdot 3\left(\mathrm{H}_{2} \mathrm{O}\right)\right)$ are formed. The absence of ASR products in the absence of $\mathrm{Ca}$ underlines that $\mathrm{Ca}$ is necessary to form ASR products in agreement with observations in synthetic systems [22] and with the presence of some calcium observed in ASR products formed in field concrete [11][19][20]. In contrast, a complete reaction of amorphous silica is observed for the samples containing $\mathrm{Ca}$ as seen by the absence of reflection at $26^{\circ} 2 \theta$ from the XRD patterns. In sample C-S-H_Na the formation of $\mathrm{C}-\mathrm{S}-\mathrm{H}$ gel is observed at relatively high $\mathrm{Ca} / \mathrm{Si}$ ratio and low $\mathrm{Na} / \mathrm{Si}$ ratio.

At initial $\mathrm{Ca} / \mathrm{Si}$ ratio of 0.25 and $(\mathrm{K}+\mathrm{Na}) / \mathrm{Si}$ of 0.5 , the formation of reaction products with high crystallinity and basal spacing of $13.1 \AA$ is observed for the SKC samples with their XRD pattern matching well with the recently investigated natural mineral shlykovite, $\mathrm{KCa}\left[\mathrm{Si}_{4} \mathrm{O}_{9}(\mathrm{OH})\right] \cdot 3 \mathrm{H}_{2} \mathrm{O}[32]$, which has a layered silicate structure with its $\mathrm{SiO}_{4}{ }^{4-}$ tetrahedron charge balanced by $\mathrm{K}^{+}$and $\mathrm{Ca}^{2+}$ in the main layer and by $\mathrm{H}^{+}$in the interlayer [33] as shown in Fig. 4. Moreover, the XRD pattern of the SNC sample shows a similar basal spacing of 13.1 $\AA$ ( $7.7^{\circ} 2 \theta$, Fig. 3). The high similarity of the XRD patterns of SKC and SNC samples suggests that $\mathrm{K}^{+}$ions in shlykovite may be fully exchanged by $\mathrm{Na}^{+}$ions without altering the basic structure, which will be discussed in the following section. Hereafter, we denote the lab-synthesized shlykovite-like structure as K-shlykovite and Na-shlykovite when the alkali cations are merely $\mathrm{K}$ and $\mathrm{Na}$, respectively. K-shlykovite is also observed in the sample $\mathrm{SK}_{0.43} \mathrm{~N}_{0.07} \mathrm{C}$ where $\mathrm{K}^{+}$is partially replaced by $\mathrm{Na}^{+}$at a $\mathrm{K} / \mathrm{Na}$ ratio of 6.1 . 
At low $\mathrm{K} / \mathrm{Na}$ ratios of 1.0 and 2.3, another not yet identified phase, hereafter denoted as ASR-P1, is consistently observed with two major broad reflections observed at $7^{\circ}$ and $33^{\circ} 2 \theta$, respectively. Comparison of these reflections with those of C-S-H formed in the C-S-H_Na sample at relatively higher $\mathrm{Ca} / \mathrm{Si}$ ratio of 0.3 and lower $\mathrm{Na} / \mathrm{Si}$ ratio of 0.25 indicates that the ASR-P1 phase is different from the C-S-H phase. In addition, formation of the ASR-P1 phase is also observed in $\mathrm{SKC}$ and $\mathrm{SK}_{0.43} \mathrm{~N}_{0.07} \mathrm{C}$ samples, however ASR-P1 is not present in sample SNC in the absence of K. It is worth to mention that synthesis of SKC is repeated with weekly shaking during the synthesis (noted as SKC\#). Interestingly, K-shlykovite is obtained without formation of ASR-P1 phase as seen from the XRD pattern for the sample SKC\#.

\subsection{Structural characterization of the synthesized reaction products}

\subsubsection{Structure refinements}

The XRD of SKC\# measured with synchrotron X-ray and SNC measured with conventional X-ray are used to refine the crystallographic parameters based on modified shlykovite structure. $\mathrm{The} \mathrm{Ca} / \mathrm{Si}$ and alkali/Si in the natural shlykovite are both 0.25 , whereas in the synthesized shlykovites they are in the range of $0.29-0.32$ and $0.35-0.41$, respectively. The significantly increased alkali/Si ratio may indicate the uptake of $\mathrm{K}(\mathrm{Na})$ into the interlayer region of shlykovite, as observed in the natural mineral cryptophyllite [33]. Therefore, modified shlykovite structures of different $\mathrm{K}(\mathrm{Na}) / \mathrm{Si}$ ratio are evaluated in the refinement of the XRD patterns for the SKC\# and SNC samples as shown in Fig. 5. Initially, two K atoms are placed at fractal coordinates $\left(\begin{array}{lll}0.5 & 0 & 0\end{array}\right)$ and $\left(\begin{array}{lll}0.5 & 0.5 & 0.5\end{array}\right)$ in one unit cell of shlykovite. To investigate the influence of interlayer $\mathrm{K}(\mathrm{Na})$ to the diffraction behavior, their occupancies are fixed to be $0,0.5,1.0$ and 1.5 , resulting in a interlayer $\mathrm{K}(\mathrm{Na}) / \mathrm{Si}$ ratio increasing from 0 to $3 / 16$. The lattice constants, anisotropic crystallite size and the $x$ - and $y$-positions of the added interlayer $\mathrm{K}$ are refined. As shown in Fig. 5a, with increasing interlayer $\mathrm{K} / \mathrm{Si}$ ratio, the calculated intensity of (002) and (004) diffraction significantly decreases and diverges from the experimental data, while the (102), (106) and peaks near $0.336 \AA^{-1}$ exhibit increasing intensity from calculation. Via refining the occupancy of interlayer $\mathrm{K}$, the best fit was obtained 
when the occupancy of interlayer $\mathrm{K}$ is 0.45 , corresponding to an interlayer $\mathrm{K} / \mathrm{Si}$ ratio of $0.9 / 16$, and an overall $\mathrm{K} / \mathrm{Si}$ ratio of 0.31 . The corresponding lattice constants were refined to be $a=$ 6.485(9), $b=6.990(4), c=26.642(7)$ and $\beta=94.7^{\circ}$, which are very close to those of the natural shlykovite. However, using the natural shlykovite structure $\left(\mathrm{P} 2_{1} / \mathrm{c}\right)$, two clear diffractions (between $0.242 \AA^{-1}$ and $0.251 \AA^{-1}$ ) are predicted but not observed in the experimental data. In contrast to natural shlykovite, the crystallite size of the synthesized K-shlykovite was refined to be $1720 \mathrm{~nm}$ along $a$-axis, $330 \mathrm{~nm}$ along $b$-axis and $600 \mathrm{~nm}$ along $c$-axis, which indicates that synthesized K-shlykovite has larger crystal size along one direction than the other two directions.

Similar strategy was also applied in refining the SNC data by replacing the $\mathrm{K}$ with $\mathrm{Na}$ in the shlykovite structure. Note that we did not intend to refine the line broadening of diffraction peaks since the instrument conditions of the conventional XRD were not calibrated. As shown in Fig. 5b, the merge of peak (004) and (100) in Na-shlykovite $\left(0.151 \AA^{-1}\right)$ is readily obtained by refining the lattice constants. Using the natural shlykovite structure $\left(\mathrm{P} 2{ }_{1} / \mathrm{c}\right)$, the $(002)$ and (102) peaks are hardly fitted. Several diffractions are predicted but not observed in the experimental data. We then reduced the symmetry from $\mathrm{P} 2{ }_{1} / \mathrm{c}$ to $\mathrm{Pc}$, and added interlayer $\mathrm{Na}$, followed by a refinement of its $x$ - and $y$-positions. The Pc symmetry clearly improves the fitting, although some predicted peaks are still not observed in the experimental data. Increased $\mathrm{Na}$ in the interlayer seems to decrease the intensity of (002) and (004)\&(100) diffraction intensity from calculation, resulting in a less satisfactory fitting to the experimental data. The best fit is obtained when the interlayer $\mathrm{Na}$ occupancy is 0 , corresponding to a $\mathrm{Na} / \mathrm{Si}$ of 0.25 . The lattice constants were refined to be $a=6.605(2), b=7.012(1), c=26.516(4)$ and $\beta=94.0^{\circ}$. The Na-shlykovite exhibits a clear increase in lattice parameter $a$, compared with SKC\#.

\subsection{2 ${ }^{29}$ Si MAS NMR}

The ${ }^{29} \mathrm{Si}$ MAS NMR spectra of the studied samples are shown in Fig. 6. For the C-S-H_Na sample, the spectrum contains resonances centered at $-82 \mathrm{ppm}$ (shoulder) and -85 ppm corresponding to bridging silica tetrahedral $\left(Q^{2 b}\right)$ and pair silica tetrahedral $\left(Q^{2 p}\right)$, which 
is similar to those reported in literature for C-S-H [21][34]. A broad peak centered at -111 ppm related to unreacted amorphous silica $\left(Q^{4}\right)$ has also been observed. A shoulder at -94 ppm as well as the signals in the range of -99 to -103 ppm are assigned to $\mathrm{Q}^{3}$ ( $\left.\mathrm{Si}-\mathrm{OH}\right)$ sites in hydrated amorphous silica [34]. Signals in the range of -99 to $-103 \mathrm{ppm}$ had also been reported in systems where amorphous siliceous aggregates reacted with alkali solution in the absence of calcium [35].

The ${ }^{29}$ Si MAS NMR spectrum of the "pure" K-shlykovite formed in the sample SKC\# is dominated by resonances at $-90,-92$ and $-94 \mathrm{ppm}$ corresponding to $\mathrm{Q}^{3}$ sites from shlykovite. The peak assignments are supported by the molecular structure of shlykovite reported in [33] as shown in Fig. 4, where only four equal numbers of $\mathrm{Q}^{3}$ sites are present with two of them sharing similar chemical environment resulting in the major peak observed at $-94 \mathrm{ppm}$. Minor peaks at $-85,-96$, and $-109 \mathrm{ppm}$ are also observed in the SKC sample corresponding to minor impurities of $\mathrm{Q}^{2}$, Si-OH group in hydrated amorphous silica $\left(\mathrm{Q}^{3}\right)$ and a trace of well-ordered silica $\left(Q^{4}\right)$. In contrast to the SKC\# sample, the ${ }^{29}$ Si MAS NMR spectrum of SNC sample shows broad line shape, which can be explained by the lower symmetry of silicate structure as indicated by XRD refinement showing that the a-axis of Na-shlykovite is stretched. Overall, the NMR peaks are also dominated by $\mathrm{Q}^{3}$ sites centered at $-94.5 \mathrm{ppm}$ with a shoulder at $-96 \mathrm{ppm}$, which overlaps with part of the spectrum of the SKC\# sample.

The $\mathrm{SK}_{0.25} \mathrm{~N}_{0.25} \mathrm{C}$ and $\mathrm{SK}_{0.35} \mathrm{~N}_{0.15} \mathrm{C}$ samples with formation of the ASR-P1 observed from XRD are also analyzed by ${ }^{29} \mathrm{Si}$ MAS NMR. Their ${ }^{29} \mathrm{Si}$ NMR spectra show that the silicate species are dominated by $\mathrm{Q}^{3}$ sites at $-90.4 \mathrm{ppm}$. Trace of $\mathrm{Q}^{2}$ site is observed at -84.6 ppm for these two samples, which could also be related to the presence of ASR-P1 or formation of minor amount of C-S-H. Formation of both K-shlykovite and ASR-P1 phases are also observed for $\mathrm{SK}_{0.43} \mathrm{~N}_{0.07} \mathrm{C}$ sample according to ${ }^{29} \mathrm{Si}$ MAS NMR spectrum, which is consistent with the observation from XRD pattern shown in Fig. 3. 


\subsubsection{Raman spectra}

The Raman spectra of the studied samples are shown in Fig. 7, where intense peaks are observed in the frequency range $200-1200 \mathrm{~cm}^{-1}$ with peak assignments given in Table 3 . Each spectrum shows peaks falling into four ranges: (i) high frequency range of Si-O symmetrical stretching vibrations $\left(800-1150 \mathrm{~cm}^{-1}\right)$, (ii) low frequency range of Si-O-Si symmetrical bending vibrations $\left(600-700 \mathrm{~cm}^{-1}\right)$, (iii) internal deformation of the Si-O tetrahedra $\left(400-500 \mathrm{~cm}^{-1}\right)$, and (iv) Ca-O polyhedra and lattice vibrations $\left(200-350 \mathrm{~cm}^{-1}\right)$ [36][37]. In addition, symmetrical C-O stretching vibrations at about $1070 \mathrm{~cm}^{-1}$ for carbonate groups [36][38] may also be identified. As seen in Fig. 7, the C-S-H phase shows vibrations at $320,430,669,882,1011,1078 \mathrm{~cm}^{-1}$, similar to those observed by others [39][38]. However, the intensity of the peak associated with $\mathrm{Ca}-\mathrm{O}$ at about $320 \mathrm{~cm}^{-1}$ is relatively low as a result of the low $\mathrm{Ca} / \mathrm{Si}$ ratio of the $\mathrm{C}-\mathrm{S}-\mathrm{H}$ phase synthesized in the present study. The intensity of peaks associated with internal deformation of the Si-O tetrahedra of $\mathrm{Q}^{4}$ tetrahedral sites at $430 \mathrm{~cm}^{-1}$ and symmetrical stretching vibrations of Si-O tetrahedra at 882 $\mathrm{cm}^{-1}$ are also very low indicating a substantial reaction extent of the amorphous silica. The dominant peaks associated with symmetrical bending at $669 \mathrm{~cm}^{-1}$ and symmetrical vibrations at $1011 \mathrm{~cm}^{-1}$ are both attributed to the $\mathrm{Q}^{2}$ tetrahedral sites according to previous studies [36], which is consistent with ${ }^{29} \mathrm{Si}$ MAS NMR results presented in Fig. 6. Minor peak associated with symmetrical C-O stretching vibrations at $1078 \mathrm{~cm}^{-1}$ is also observed for this sample as a result of slight carbonation of the C-S-H phase.

For the $\mathrm{SKC}, \mathrm{SNC}$ and $\mathrm{SK}_{0.43} \mathrm{~N}_{0.07} \mathrm{C}$ samples where shlykovite is present, two major well-resolved bands attributed to symmetrical bending vibrations and stretching vibrations are observed at 594 and $1086 \mathrm{~cm}^{-1}$, respectively, as compiled in Table 4. Several studies have assigned them to $\mathrm{Q}^{3}$ species of silica tetrahedra [36][38][40]. The results are consistent with the NMR observations addressed above for these samples and with the known structure of shlykovite. For the $\mathrm{SK}_{0.25} \mathrm{~N}_{0.25} \mathrm{C}$ and $\mathrm{SK}_{0.35} \mathrm{~N}_{0.15} \mathrm{C}$ samples, two well-resolved peaks attributed to symmetrical bending vibrations of Si-O-Si is observed at 638 and $675 \mathrm{~cm}^{-1}$, and another two well-resolved peaks attributed to symmetrical stretching vibrations of Si-O are observed 
at 1065 and $1120 \mathrm{~cm}^{-1}$. These bands reflect the characteristics of the structure of the ASR-P1 phase, whose structure has not yet been identified. Based on ${ }^{29} \mathrm{Si}$ MAS NMR spectra of these samples, it can be deduced that these bands are most likely associated with $\mathrm{Q}^{3}$ species of silica tetrahedra. The assignment of the high frequency bands (i.e., 1065 and $1120 \mathrm{~cm}^{-1}$ ) to the $\mathrm{Q}^{3}$ species for these samples are in line with those reported for $\mathrm{Q}^{3}$ in $\mathrm{C}-\mathrm{S}-\mathrm{H}$ and alkali silicate glasses [36][38][40]. However, the assignment of the low frequency bands between 630 and $670 \mathrm{~cm}^{-1}$ are generally assigned to $\mathrm{Q}^{2}$ species in C-S-H [36][38][41], which is in

contrast to the ${ }^{29} \mathrm{Si}$ NMR data in the present study. This observation may suggest a possible overlapping of $\mathrm{Q}^{2}$ and $\mathrm{Q}^{3}$ species in this range. The divesity of the assignment to $\mathrm{Q}^{2}$ and $\mathrm{Q}^{3}$ for the $630-670 \mathrm{~cm}^{-1}$ bands may be explained by the fact that the frequencies of bands in this region are very sensitive to the Si-O-Si bond angle as reviewed in [42]. In addition to these major bands, the $\mathrm{Ca}-\mathrm{O}$ vibrations and $\mathrm{Si}-\mathrm{O}$ tetrahedra of $\mathrm{Q}^{4}$ species are also observed for these samples at $240-350 \mathrm{~cm}^{-1}$ and $400-500 \mathrm{~cm}^{-1}$, respectively.

In addition to shlykovite, the ASR-P1 phase is also identified in the SKC sample as seen by the bands at $638,675,1066$ and $1120 \mathrm{~cm}^{-1}$, which is in line with the XRD measurements. For the $\mathrm{SK}_{0.25} \mathrm{~N}_{0.25} \mathrm{C}$ and $\mathrm{SK}_{0.35} \mathrm{~N}_{0.15} \mathrm{C}$ samples, mainly the ASR-P1 phase is observed, although a low quantity of C-S-H might also be present. The bands associated with all the identified phases are summarized in Table 4.

\subsubsection{FTIR}

Compared to the Raman spectra, the FTIR spectra in Fig. 8a show broader signals. The spectra indicate the presence of mainly unreacted amorphous silica in the K-gel and Na-gel samples by the broad band centered at $1050 \mathrm{~cm}^{-1}$ and an additional band centered at $790 \mathrm{~cm}^{-1}$, which shift slightly to lower wavenumbers compared to the bands of amorphous silica at 1070 and $800 \mathrm{~cm}^{-1}$ plotted in the same figure. For the C-S-H_Na sample, the Si-O stretching vibrations of $\mathrm{Q}^{2}$ species associated with $\mathrm{C}-\mathrm{S}-\mathrm{H}$ phase are observed at $966 \mathrm{~cm}^{-1}$, while the band attributed to the minor amount of unreacted amorphous silica is observed at $1087 \mathrm{~cm}^{-1}$. 
Similar characterization bands for C-S-H samples have also been reported in literature $[43][44][45]$.

For the samples containing shlykovite and/or ASR-P1, the FT-IR spectra show bands in the range $1130-950 \mathrm{~cm}^{-1}$ originating from asymmetric and symmetric stretching vibrations of Si-O bonds, and bands in the range $700-600 \mathrm{~cm}^{-1}$ corresponding to Si-O-Si bending vibrations [43]. A close examination of the broad band in the range $1130-950 \mathrm{~cm}^{-1}$ reveals presence of several distinct Si-O-Si bonds in the reaction products for the samples containing $\mathrm{K}$, although XRD data shows completely different crystallinity between ASR-P1 and shlykovite (Fig.3). For the SKC sample, the following different stretching vibrations of Si-O-Si bonds are identified at 1132, 1098, 1023, 996, $960 \mathrm{~cm}^{-1}$, which are identical to those observed for the natural shlykovite [32]. A band observed at $877 \mathrm{~cm}^{-1}$ for $\mathrm{SK}_{0.35} \mathrm{~N}_{0.15} \mathrm{C}$ and SKC is attributed to out-of-plane bending of $\mathrm{CO}_{3}{ }^{2-}$ [43]. The distinction of shlykovite and ASR-P1 can be better visualized by the characteristic peak of these phases in the second derivative of the FTIR curves as shown in Fig. $8 \mathrm{~b}$. The results show formation of $\mathrm{K}$-shlykovite in the SKC and $\mathrm{SK}_{0.43} \mathrm{~N}_{0.07} \mathrm{C}$ samples, and formation of ASR-P1 phases in the $\mathrm{S}_{0.25} \mathrm{~K}_{0.25} \mathrm{NC}, \mathrm{SK}_{0.35} \mathrm{~N}_{0.15} \mathrm{C}$ and $\mathrm{SK}_{0.43} \mathrm{~N}_{0.07} \mathrm{C}$ samples, which confirms the observations from XRD, ${ }^{29}$ Si MAS NMR, and Raman spectroscopy. The features FTIR peaks associated with these phases are also summarized in Table 4.

In addition to the asymmetric and symmetric stretching vibrations of $\mathrm{Si}-\mathrm{O}$ bonds addressed above, the stretching vibrations of $\mathrm{O}-\mathrm{H}$ groups in $\mathrm{H}_{2} \mathrm{O}$ or hydroxyls with a wide range of hydrogen bond strength is also observed from FTIR spectra from the broad band at $2400-3800 \mathrm{~cm}^{-1}$ as shown in Fig. 9. The broad band within this range for the K-gel sample is associated with the gel water or loosely bound water. For the C-S-H_Na sample, two broad bands centered at 3580 and $3395 \mathrm{~cm}^{-1}$ are observed. The $3580 \mathrm{~cm}^{-1}$ band can be assigned to the stretching vibration of non- or weakly-hydrogen-bonded hydroxyl groups in $\mathrm{CaOH}$ linkages in the main layer as also observed in other study [43]. The $3395 \mathrm{~cm}^{-1}$ band is probably related to $\mathrm{O}-\mathrm{H}$ stretching of more strongly hydrogen bonded molecular $\mathrm{H}_{2} \mathrm{O}$ in the interlayer. The bands associated with the main layer water and interlayer water are also 
observed in $\mathrm{SNC}$, $\mathrm{SKC}$ and $\mathrm{SK}_{0.43} \mathrm{~N}_{0.07} \mathrm{C}$ samples as shown in Fig. 9. The assignments of these peaks are supported by the molecular structure of the shlykovite, which shows the presence of both $\mathrm{OH}$ group and loosely bound water. The narrowness of the band associated with the $\mathrm{OH}$ groups, indicates that this types of water is well-defined ordered sites. A small peak at $2970 \mathrm{~cm}^{-1}$ is also observed due to the trace of contamination of the samples by the ethanol used to wash the solid after filtration. In contrast, the samples containing mainly ASR-P1, show only a broad signal relatively weak signal in this range, indicating the absence of well-ordered OH-groups.

\subsubsection{TGA}

The results obtained from thermogravimetric analysis (TGA) on the studied samples are shown in Fig. 10. For the three reference samples, i.e., K-gel, Na-gel and C-S-H_Na, only a gradual loss of weight from $30{ }^{\circ} \mathrm{C}$ up to $400{ }^{\circ} \mathrm{C}$ is observed. For samples $\mathrm{SK}_{0.25} \mathrm{~N}_{0.25} \mathrm{C}$ and $\mathrm{SK}_{0.35} \mathrm{~N}_{0.15} \mathrm{C}$ with formation of only ASR-P1 phase according to XRD results, similar weight loss curves as for silica gel and C-S-H are observed, indicating that these solids contain relatively little water and that this water is poorly confined. The low temperature at which the weight losses of amorphous silica, C-S-H and ASR-P1 phases occurs is most likely related to the presence of free or loosely bound water at the surface or in the C-S-H interlayer.

Multi-step weight losses are observed for the other samples with formation of shlykovite phases, i.e., SKC\#, SNC and $\mathrm{SK}_{0.43} \mathrm{~N}_{0.07} \mathrm{C}$. The weight losses up to $200{ }^{\circ} \mathrm{C}$ indicate the presence of some free or loosely bound water. Additional loss of water between 200 and $400^{\circ} \mathrm{C}$ could be associated with water loss from the $\mathrm{OH}$ group of the reaction products. The total weight loss observed up to $400{ }^{\circ} \mathrm{C}$ for $\mathrm{SKC} \#$ corresponds to $0.78 \pm 0.08 \mathrm{H}_{2} \mathrm{O}$ per $\mathrm{Si}$, consistent with the $0.87 \mathrm{H}_{2} \mathrm{O}$ per $\mathrm{Si}$ suggested for K-shlykovite [32]. The water loss up to $400{ }^{\circ} \mathrm{C}$ for SNC sample corresponds to $0.95 \mathrm{H}_{2} \mathrm{O}$ per Si, indicating the presence of slightly

more water. The observation of loosely bound water and water in $\mathrm{OH}$ groups from DTG results confirm the observations from FTIR measurements (Fig. 9). 
In summary, the solid phase analyses indicate that amorphous silica remains unreacted in the absence of calcium. At high initial $\mathrm{Ca} / \mathrm{Si}$ ratio and low alkali/Si ratio, $\mathrm{C}-\mathrm{S}-\mathrm{H}$ is formed, while ASR products are formed for samples with low $\mathrm{Ca} / \mathrm{Si}$ of 0.25 and high alkali/Si ratio of 0.5. K-shlykovite is formed when only $\mathrm{K}$ is the alkali source or at high $\mathrm{K} / \mathrm{Na}$ ratio of 6.1 . Na-shlykovite is formed when only $\mathrm{Na}$ is the alkali source. Poorly crystalline ASR-P1 is formed in samples containing $\mathrm{K}$ except for the sample SKC\# which was shaken weekly during synthesis.

\subsection{Volume stability}

The most widely reported hypothesis regarding expansion of concrete caused by ASR is swelling of the ASR products after absorbing water. In this regard, the water uptake capacity and the volume stability of synthesized ASR products under moist conditions are of importance. The water vapor isotherm measured by dynamic vapor sorption (DVS) method is shown in Fig. 11. The measurement was performed on the samples after vacuum drying in desiccator. The data are normalized by the weight loss determined by TGA at $600{ }^{\circ} \mathrm{C}$, i.e., $16.15 \%$ (SNC), $12.15 \%$ (SKC\#), 10.73\% $\left(\mathrm{SK}_{0.43} \mathrm{~N}_{0.07} \mathrm{C}\right)$ and $11.9 \%\left(\mathrm{SK}_{0.25} \mathrm{~N}_{0.25} \mathrm{C}\right)$. For comparison, the result for synthesized $\mathrm{C}-\mathrm{S}-\mathrm{H}$ with $\mathrm{Ca} / \mathrm{Si}$ ratio of 1.6 from a previous study [46] is plotted in the same figure. Overall, gradual water absorption is observed for all samples within the relative humidity $(\mathrm{RH})$ range of $35-75 \%$. Over this range, water molecules are likely absorbed in interlayer space (in the case of C-S-H) as well as on external surfaces of the reaction products, as e.g. also observed for C-S-H phases [47]. At high relative humidity capillary condensation is observed; this is more distinct for the amorphous ASR-P1 than for the well crystalline shlykovite. Both shlykovite and ASR-P1 show less water uptake than C-S-H, where water is bound in the interlayer space as well as in the interparticle space as gel water [48]. During desorption, a hysteresis is obtained for all samples, as typical for C-S-H phase shown in Fig. 11 and [47] and clay minerals [49]. However, the synthesized ASR products in this study have relatively lower water uptake capacity and smaller hysteresis compared to the C-S-H phase. 
As DVS measurement only measure the water uptake within the solids without direct differentiation whether the water is taken up in the interlayer or on the surface, the effect of water uptake on the structure is also investigated by XRD. The results in Fig. 12 show the XRD pattern of the K-shlykovite and Na-shlykovite before and after drying. The results show that no increase of basal d-spacing $\left(13.1 \AA\right.$ or $\left.7.7^{\circ} 2 \theta\right)$ is observed for the synthesized crystalline ASR products, which suggest that the uptake of water by the synthesized ASR products observed in the DVS results is likely related to the water absorption on the surface and interstice of the particles of shlykovite. The above observations are further confirmed by the DTG measurements where the SKC\# sample with formation of only K-shlykovite was exposed to $100 \%$ relatively humidity $(\mathrm{RH})$ or mixed with smaller amount of water before TGA measurement. The DTG results shown in Fig. 13 confirm that the shlykovite structure remains unchanged as reflected by the unaltered amount of loosely bound water and $\mathrm{OH}$ groups. This phenomenon is different from most of the layer silicate minerals, such as clay minerals and C-S-H, where water can also be absorbed in their interlayer space. The results suggest that ASR expansion may not be caused by swelling of the ASR products but by alternative mechanism such as e.g. crystallization pressure. The high RH known to play a significant role in ASR may be related to the chemical reaction itself or to the transport of the alkali and $\mathrm{Ca}$ ions into the relative sites within the aggregates.

\section{$3.5 \mathrm{pH}$ and measured concentration of the solution}

The measured concentrations of $\mathrm{Si}, \mathrm{Ca}, \mathrm{Na}$ and $\mathrm{K}$ of the solutions in the supernatants together with calculated $\mathrm{OH}^{-}$ion concentrations from measured $\mathrm{pH}$ are shown in Table 5 . High silicon concentrations are observed for the Na-gel and K-gel samples in the absence of calcium, indicating that silica was partially dissolved by the alkali solution but no or little precipitation of new solids. When $\mathrm{CaO}$ is present in the starting materials, the silicon concentration at equilibrium is substantially decreased, indicating the reaction of calcium with silicon to solid phases. In the case of C-S-H_Na sample where C-S-H is formed, highest calcium concentration at equilibrium is observed. However, the calcium concentrations of the 
other Ca-containing samples, where shlykovite and/or ASR-P1 are formed, are low and even comparable to those of Na-gel and K-gel samples where the measured trace of calcium is attributed to the impurity of the raw materials. The results indicate that nearly all calcium in these samples has reacted to form shlykovite and/or ASR-P1 phase. Comparing the $\mathrm{K}$ and $\mathrm{Na}$ concentrations between the equilibrium solution (Table 5) and the starting solution (Table 1), a substantial decrease of alkali ion concentration is observed for all samples. The reaction of alkalis with silica is also observed when comparing their concentrations between initial and equilibrium solutions as shown in Fig. 14. Overall, a strong reduction of alkali concentration is observed for all Ca-containing samples, indicating the uptake of alkalis in the solid phases. Linear correlations between the initial and equilibrium concentrations of $\mathrm{K}$ and $\mathrm{Na}$ are observed. The slightly lower slope for $\mathrm{K}$ binding curve than $\mathrm{Na}$ binding curve suggest that $\mathrm{K}$ is more favorably bound in the solids than $\mathrm{Na}$ for the studied samples. In contrast to the Ca-containing samples, negligible uptake of alkalis in solids is observed for the Na-gel and K-gel samples. These observations suggest that almost all of the reacted alkalis in the Na-gel and K-gel samples remained in solution.

\subsection{Saturation indices}

The saturation indices calculated by GEMs software for all samples based on the measured concentrations are summarized in Table 5. As expected, the saturation indices with respect to $\mathrm{C}-\mathrm{S}-\mathrm{H}$ are negative for the K-gel and Na-gel samples, due to the absence of Ca. However, also the saturation indices with respect to amorphous silica are slightly negative, although unreacted silica had been clearly seen by XRD in Fig. 3. Similarly the saturation indices for the C-S-H_Na sample with respect to amorphous silica and C-S-H are both slightly negative, although presence of unreacted silica and formation of C-S-H are observed from other measurements such as XRD and ${ }^{29} \mathrm{Si}$ MAS NMR. These apparent discrepancies are related to high silicon concentrations and relatively high temperature of $80{ }^{\circ} \mathrm{C}$. The thermodynamic databases [29][30] used, i) describes only poorly the aqueous silica complexes at such high silica concentration of up to $0.9 \mathrm{M}$ as observed for the Na-gel and K-gel samples, ii) misses 
high temperature parameters for polynuclear silica species, and iii) has poorly defined temperature behavior of amorphous silica and C-S-H, which makes calculation of saturation indices less accurate. This indicates the need for more advanced amorphous $\mathrm{SiO}_{2}$ and C-S-H models valid at higher temperature as well as advances in the description of aqueous silica species at high concentrations and temperatures to be able to better take into account the effect of temperature and very high Si concentrations. Independently of these restrictions, the calculated saturation indices results show that the saturation indices with respect to C-S-H and amorphous silica are more negative for the samples with formation of ASR products, i.e., $\mathrm{Na}(\mathrm{K})$-shlykovite and/or ASR-P1, consistent with the other measurements that no major C-S-H and amorphous silica are formed in these samples.

\subsection{Comparison with ASR product formed in concrete}

The possibility to thoroughly characterize synthesized ASR products is expected to further our understanding of ASR products formed in field samples. Thus the synthesized ASR products are compared with ASR products formed in concrete. The SEM imagines shown in Fig. 15 demonstrate the morphologies of the different synthesized ASR products. Nano-crystalline texture is observed for the ASR-P1 phase formed both in the $\mathrm{SK}_{0.25} \mathrm{~N}_{0.25} \mathrm{C}$ and $\mathrm{SK}_{0.43} \mathrm{~N}_{0.07} \mathrm{C}$ samples. In contrast, plate-like and fiber-like morphologies are observed for Na-shlykovite and K-shlykovite, respectively. The observations of nano-crystalline and crystalline products from SEM measurements for the corresponding samples confirm the structural information obtained from the other techniques presented in previous sections. The morphologies of the synthesized K-shlykovite and ASR-P1 are somewhat different to the crystalline ASR products formed in concrete aggregates, which usually have plate-like morphology often forming typical rosettes independent of concrete mixtures and binder types $[8][11][50][51]$. The platelets of Na-shlykovite strongly resemble the product formed in concrete.

Some limited differences in the crystal structure is further confirmed by the comparison of XRD patterns of the K-shlykovite and Na-shlykovite formed in the SKC\# and SNC samples 
with XRD pattern obtained by synchrotron-based micro-X-ray diffraction (micro-XRD) for the crystalline ASR products formed in an air void of a concrete collected from a 40 year old bridge in Mels, Switzerland, (labeled as Mels_03). As seen in Fig. 16, strong similarities are observed at reflections between $0.146 \AA^{-1}$ and $0.382 \AA^{-1}$, although the field sample has much broader, less well defined peaks. However, a lower basal spacing is observed for the Mels sample than for the lab-synthesized ASR products. This difference is even bigger compared with another ASR product formed in an aggregate (Dähn et al. [19]) of the same bridge where sample Mels-03 was obtained as shown in Fig. 16.

Despite the differences in basal spacing observed by XRD, the Raman spectra in Fig. 17 show high similarity of the molecular structure in short-range order among K-shlykovite, Na-shlykovite and ASR products formed in aggregates during the concrete prism test [52], and in aggregate of the bridge [20]. In particular the Raman spectrum for K-shlykovite is almost identical to that of ASR product from the concrete prism test (where the samples had been subjected to $60{ }^{\circ} \mathrm{C}$ for 20 weeks), indicating similar local environment of the Si species and also of the Ca environment as reflected by the band at about $320 \mathrm{~cm}^{-1}$ observed for both K-shlykovite and the ASR product from the concrete prism test. The field sample which has not been exposed to such high temperatures [20], shows similar features, but the positions of the peaks at 600 and $1100 \mathrm{~cm}^{-1}$ is somewhat shifted. The results tentatively indicate that the obtained K-shlykovite and Na-shlykovite could in fact be a synthetic proxy for some of the ASR products observed in the field.

\section{Conclusions}

In this study, ASR products with initial $\mathrm{Ca} / \mathrm{Si}$ ratio of $0.25,(\mathrm{~K}+\mathrm{Na}) / \mathrm{Si}$ ratio of 0.5 and different $\mathrm{K} / \mathrm{Na}$ ratios have been synthesized at $80^{\circ} \mathrm{C}$. The observed products had $\mathrm{Ca} / \mathrm{Si} \approx 0.3$ and alkali/ $\mathrm{Si} \approx 0.4$. This range of composition corresponds to the ASR products formed in aggregates of ASR-affected concrete structures. Different techniques were applied to characterize the reaction products. The solution chemistry and saturated indices were also evaluated. Based on the results and discussion, the following conclusions can be drawn: 
(i) In addition to reactive silica, the formation of ASR products requires the presence of both alkalis and calcium. Without calcium, the main reaction products are amorphous silica; at high $\mathrm{Ca} / \mathrm{Si}$ ratio and low alkali/Si ratio, C-S-H phase is formed, while ASR products formed at low calcium concentrations and high alkali concentrations. Na-shlykovite is formed in presence of $\mathrm{Ca}$, when $\mathrm{Na}$ is the only alkali. K-shlykovite is formed in presence of $\mathrm{Ca}$ when $\mathrm{K}$ is the only alkali or at high $\mathrm{K} / \mathrm{Na}$ ratio of 6.1. A nano-crystalline product labeled ASR-P1 phase is observed in the presence of both $\mathrm{K}$ and $\mathrm{Na}$, preferably at lower $\mathrm{K} / \mathrm{Na}$ ratios 1.0 and 2.3.

(ii) In contrast to C-S-H, the silica structures of both shlykovite and ASR-P1 phase are dominated by $\mathrm{Q}^{3}$ species indicating a silicate sheet structure, similar to ASR products from field concrete. In particular, Raman spectra of K-shlykovite are identical to that of ASR product formed in aggregates during the concrete prism test. The general similarity between synthesized ASR products (shlykovite) and crystalline ASR products observed in field samples suggests that the structure information obtained for the K-shlykovite and Na-shlykovite can be used to better understand the structure and formation condition of ASR products in concrete.

(iii) The experimental results show that the water uptake capacity and hysteresis effect during the wet-dry cycle are smaller or comparable to C-S-H phases. The XRD and DTG results suggest that the structure of the synthesized ASR products remained unchanged after absorption of water, suggesting that they are not swelling. However, more work needs to be done to validate whether ASR products formed in concrete uptake the water into interlayer or not at elevated $\mathrm{RH}$, as these data are not available so far.

\section{Acknowledgement}

The authors would like to thank the following two funding resources for this research: (a) SNF Sinergia: Alkali-silica reaction in concrete (ASR), grant number CRSII5_17108; (b) European Union's Horizon 2020 research and innovation programme under the Marie 
Skłodowska-Curie grant agreement number 754364 and number 701647 . Luigi Brunetti is acknowledged for measurement of the ion concentration of the solution, and Daniel Rentsch for acquiring all the ${ }^{29} \mathrm{Si}$ MAS NMR spectra. Frank Winnefeld is acknowledged for help and discussion with XRD measurement and results, Mateusz Wyrzykowski for help with DVS measurement, Douglas Robinson for help with the XRD measurement in beamline 6-ID-D at Advanced Photon Source, and Jørgen Skibsted for helpful discussions on the ${ }^{29}$ Si MAS NMR spectra. 


\section{References}

[1] T.E. Stanton, Influence of cement and aggregate on concrete expansion, Eng. News-Record. (1940).

[2] M. Thomas, B. Fournier, K. Folliard, J. Ideker, M. Shehata, Test methods for evaluating preventive measures for controlling expansion due to alkali-silica reaction in concrete, Cem. Concr. Res. 36 (2006) 1842-1856.

[3] R.N. Swamy, Role and effectiveness of mineral admixtures in relation to alkali-silica reaction, in: Alkali-Silica React. Concr., CRC Press, 2002: pp. 112-137.

[4] M. Thomas, The effect of supplementary cementing materials on alkali-silica reaction: A review, Cem. Concr. Res. 41 (2011) 1224-1231.

[5] J. Lindgård, Ö. Andiç-Çakır, I. Fernandes, T.F. Rønning, M.D.A. Thomas, Alkali-silica reactions (ASR): literature review on parameters influencing laboratory performance testing, Cem. Concr. Res. 42 (2012) 223-243.

[6] J.W. Pan, Y.T. Feng, J.T. Wang, Q.C. Sun, C.H. Zhang, D.R.J. Owen, Modeling of alkali-silica reaction in concrete: a review, Front. Struct. Civ. Eng. 6 (2012) 1-18.

[7] F. Rajabipour, E. Giannini, C. Dunant, J.H. Ideker, M.D.A. Thomas, Alkali-silica reaction: current understanding of the reaction mechanisms and the knowledge gaps, Cem. Concr. Res. 76 (2015) 130-146.

[8] T. Katayama, Petrographic study of the alkali-aggregate reactions in concrete, Grad. Sch. Sci. Univ. Tokyo, Dep. Earth Planet. Sci. (2012).

[9] A. Leemann, P. Lura, E-modulus of the alkali-silica-reaction product determined by micro-indentation, Constr. Build. Mater. 44 (2013) 221-227.

[10] A. Leemann, C. Merz, An attempt to validate the ultra-accelerated microbar and the concrete performance test with the degree of AAR-induced damage observed in concrete structures, Cem. Concr. Res. 49 (2013) 29-37.

[11] A. Leemann, T. Katayama, I. Fernandes, M.A.T.M. Broekmans, Types of alkaliaggregate reactions and the products formed, Proc. Inst. Civ. Eng. Mater. 169 (2016) $128-135$. 
[12] C.L. Collins, J.H. Ideker, G.S. Willis, K.E. Kurtis, Examination of the effects of LiOH, LiCl, and LiNO3 on alkali-silica reaction, Cem. Concr. Res. 34 (2004) 1403-1415.

[13] X. Feng, M.D.A. Thomas, T.W. Bremner, B.J. Balcom, K.J. Folliard, Studies on lithium salts to mitigate ASR-induced expansion in new concrete: a critical review, Cem. Concr. Res. 35 (2005) 1789-1796.

[14] W.F. Cole, C.J. Lancucki, M.J. Sandy, Products formed in an aged concrete, Cem. Concr. Res. 11 (1981) 443-454.

[15] C.J. Benmore, P.J.M. Monteiro, The structure of alkali silicate gel by total scattering methods, Cem. Concr. Res. 40 (2010) 892-897.

[16] W. Wieker, C. Hübert, D. Heidemann, R. Ebert, Alkali-Aggregate Reaction-A Problem of the Insufficient Fundamental Knowledge of Its Chemical Base. M. Cohen, S. Mindess, J. Skalny (Eds.), in: Proc. Sidney Diam. Symp. Mater. Sci. Eng. Concr. Cem. Based Compos. Am. Ceram. Soc. Westerville, OH, 1998: pp. 395-408.

[17] W.F. Cole, C. Lancucki, Products formed in an aged concrete the occurrence of okenite, Cem. Concr. Res. 13 (1983) 611-618.

[18] L. De Ceukelaire, The determination of the most common crystalline alkali-silica reaction product, Mater. Struct. 24 (1991) 169-171.

[19] R. Dähn, A. Arakcheeva, P. Schaub, P. Pattison, G. Chapuis, D. Grolimund, E. Wieland, A. Leemann, Application of micro X-ray diffraction to investigate the reaction products formed by the alkali-silica reaction in concrete structures, Cem. Concr. Res. 79 (2016) $49-56$.

[20] A. Leemann, Raman microscopy of alkali-silica reaction (ASR) products formed in concrete, Cem. Concr. Res. 102 (2017) 41-47.

[21] X.-D. Cong, R.J. Kirkpatrick, S. Diamond, 29Si MAS NMR spectroscopic investigation of alkali silica reaction product gels, Cem. Concr. Res. 23 (1993) 811-823.

[22] A. Leemann, G. Le Saout, F. Winnefeld, D. Rentsch, B. Lothenbach, Alkali-silica reaction: the influence of calcium on silica dissolution and the formation of reaction products, J. Am. Ceram. Soc. 94 (2011) 1243-1249. 
[23] X. Hou, L.J. Struble, R.J. Kirkpatrick, Formation of ASR gel and the roles of CSH and portlandite, Cem. Concr. Res. 34 (2004) 1683-1696.

[24] X. Hou, R.J. Kirkpatrick, L.J. Struble, P.J.M. Monteiro, Structural investigations of alkali silicate gels, J. Am. Ceram. Soc. 88 (2005) 943-949.

[25] A. Leemann, B. Lothenbach, The influence of potassium-sodium ratio in cement on concrete expansion due to alkali-aggregate reaction, Cem. Concr. Res. 38 (2008) 11621168 .

[26] L. Lutterotti, S. Matthies, H.R. Wenk, MAUD: a friendly Java program for material analysis using diffraction, IUCr Newsl. CPD. 21 (1999).

[27] D.A. Kulik, T. Wagner, S. V Dmytrieva, G. Kosakowski, F.F. Hingerl, K. V Chudnenko, U.R. Berner, GEM-Selektor geochemical modeling package: revised algorithm and GEMS3K numerical kernel for coupled simulation codes, Comput. Geosci. 17 (2013) $1-24$.

[28] T. Wagner, D.A. Kulik, F.F. Hingerl, S. V Dmytrieva, GEM-Selektor geochemical modeling package: TSolMod library and data interface for multicomponent phase models, Can. Mineral. 50 (2012) 1173-1195.

[29] T. Thoenen, W. Hummel, U. Berner, E. Curti, The PSI/Nagra Chemical Thermodynamic Database 12/07, PSI report 14-04, Villigen PSI, Switzerland, (2014).

[30] B. Lothenbach, D.A. Kulik, T. Matschei, M. Balonis, L. Baquerizo, B. Dilnesa, G.D. Miron, R.J. Myers, Cemdata18: A chemical thermodynamic database for hydrated Portland cements and alkali-activated materials, Cem. Concr. Res. 115 (2019) 472-506.

[31] D.A. Kulik, Improving the structural consistency of CSH solid solution thermodynamic models, Cem. Concr. Res. 41 (2011) 477-495.

[32] I. V Pekov, N. V Zubkova, Y.E. Filinchuk, N. V Chukanov, A.E. Zadov, D.Y. Pushcharovsky, E.R. Gobechiya, Shlykovite $\mathrm{KCa}[\mathrm{Si} 4 \mathrm{O} 9(\mathrm{OH})] \cdot 3 \mathrm{H} 2 \mathrm{O}$ and cryptophyllite $\mathrm{K} 2 \mathrm{Ca}[\mathrm{Si} 4 \mathrm{O} 10] \cdot 5 \mathrm{H} 2 \mathrm{O}$, new mineral species from the Khibiny alkaline pluton, Kola peninsula, Russia, Geol. Ore Depos. 52 (2010) 767-777. 
[33] N. V Zubkova, Y.E. Filinchuk, I. V Pekov, D.Y. Pushcharovsky, E.R. Gobechiya, Crystal structures of shlykovite and cryptophyllite: comparative crystal chemistry of phyllosilicate minerals of the mountainite family, Eur. J. Mineral. 22 (2010) 547-555.

[34] T.F. Sevelsted, J. Skibsted, Carbonation of C-S-H and C-A-S-H samples studied by 13C, 27Al and 29Si MAS NMR spectroscopy, Cem. Concr. Res. 71 (2015) 56-65.

[35] X. Cong, R.J. Kirkpatrick, 29Si MAS NMR study of the structure of calcium silicate hydrate, Adv. Cem. Based Mater. 3 (1996) 144-156.

[36] R.J. Kirkpatrick, J.L. Yarger, P.F. McMillan, Y. Ping, X. Cong, Raman spectroscopy of CSH, tobermorite, and jennite, Adv. Cem. Based Mater. 5 (1997) 93-99.

[37] D. Müller, R. Hochleitner, K.T. Fehr, Raman spectroscopic investigations of natural jennite from Maroldsweisach, Bavaria, Germany, J. Raman Spectrosc. 47 (2016) 602606.

[38] S. Ortaboy, J. Li, G. Geng, R.J. Myers, P.J.M. Monteiro, R. Maboudian, C. Carraro, Effects of $\mathrm{CO} 2$ and temperature on the structure and chemistry of $\mathrm{C}-(\mathrm{A}-) \mathrm{S}-\mathrm{H}$ investigated by Raman spectroscopy, RSC Adv. 7 (2017) 48925-48933.

[39] L. Black, C. Breen, J. Yarwood, K. Garbev, P. Stemmermann, B. Gasharova, Structural features of C-S-H (I) and its carbonation in air-a Raman spectroscopic study. Part II: carbonated phases, J. Am. Ceram. Soc. 90 (2007) 908-917.

[40] G.M. Bancroft, H.W. Nesbitt, G.S. Henderson, C. O’Shaughnessy, A.C. Withers, D.R. Neuville, Lorentzian dominated lineshapes and linewidths for Raman symmetric stretch peaks $\left(800-1200 \mathrm{~cm}^{-1}\right)$ in Qn (n=1-3) species of alkali silicate glasses/melts, J. Non. Cryst. Solids. 484 (2018) 72-83.

[41] B. Lothenbach, D. Nied, G. Achiedo, A. Dauzères, Magnesium and calcium silicate hydrates, Cem. Concr. Res. 77 (2015) 60-68.

[42] P. McMillan, Structural studies of silicate glasses and melts-applications and limitations of Raman spectroscopy, Am. Mineral. 69 (1984) 622-644. 
[43] P. Yu, R.J. Kirkpatrick, B. Poe, P.F. McMillan, X. Cong, Structure of calcium silicate hydrate (C-S-H): Near-, Mid-, and Far-infrared spectroscopy, J. Am. Ceram. Soc. 82 (1999) 742-748.

[44] I. García-Lodeiro, A. Fernández-Jiménez, M.T. Blanco, A. Palomo, FTIR study of the sol-gel synthesis of cementitious gels: C-S-H and N-A-S-H, J. Sol-Gel Sci. Technol. 45 (2008) 63-72.

[45] I.G. Lodeiro, D.E. Macphee, A. Palomo, A. Fernández-Jiménez, Effect of alkalis on fresh C-S-H gels. FTIR analysis, Cem. Concr. Res. 39 (2009) 147-153.

[46] E. L’Hôpital, B. Lothenbach, D.A. Kulik, K. Scrivener, Influence of calcium to silica ratio on aluminium uptake in calcium silicate hydrate, Cem. Concr. Res. 85 (2016) 111121.

[47] C. Roosz, S. Gaboreau, S. Grangeon, D. Prêt, V. Montouillout, N. Maubec, S. Ory, P. Blanc, P. Vieillard, P. Henocq, Distribution of water in synthetic calcium silicate hydrates, Langmuir. 32 (2016) 6794-6805.

[48] A.C.A. Muller, K.L. Scrivener, A.M. Gajewicz, P.J. McDonald, Use of bench-top NMR to measure the density, composition and desorption isotherm of $\mathrm{C}-\mathrm{S}-\mathrm{H}$ in cement paste, Microporous Mesoporous Mater. 178 (2013) 99-103.

[49] L. Michot, I.A. Maslon, F. Thomas, F. Vandeuvre, Mechanism of adsorption and desorption of water vapor by homoionic montmorillonites: 2 . The $\mathrm{Li}+, \mathrm{Na}+, \mathrm{K}+, \mathrm{Rb}+$ and Cs+-exchanged forms, Clays Clay Min. 43 (1995) 324-336.

[50] Z. Shi, C. Shi, S. Wan, Z. Zhang, Effects of alkali dosage and silicate modulus on alkali-silica reaction in alkali-activated slag mortars, Cem. Concr. Res. 111 (2018) 104115. doi:10.1016/j.cemconres.2018.06.005.

[51] Z. Shi, C. Shi, J. Zhang, S. Wan, Z. Zhang, Z. Ou, Alkali-silica reaction in waterglass-activated slag mortars incorporating fly ash and metakaolin, Cem. Concr. Res. 108 (2018) 10-19.

[52] A. Leemann, The influence of lithium on the structure of ASR products in concrete, in: 15th Int. Conf. Alkali-Aggregate React., 2016. 
[53] L. Robinet, C. Coupry, K. Eremin, C. Hall, The use of Raman spectrometry to predict the stability of historic glasses, J. Raman Spectrosc. An Int. J. Orig. Work All Asp. Raman Spectrosc. Incl. High. Order Process. Also Brillouin Rayleigh Scatt. 37 (2006) 789-797. 
Table 1. Starting materials and mix proportions for the synthesis of ASR products and reference samples

\begin{tabular}{llllllllllllll}
\hline & & $\mathrm{SiO}_{2}$ & $\mathrm{CaO}$ & $\mathrm{NaOH}$ & $\mathrm{KOH}$ & $\mathrm{H}_{2} \mathrm{O}$ & $\mathrm{w} / \mathrm{s}$ & $\mathrm{Ca} / \mathrm{Si}$ & $(\mathrm{Na}+\mathrm{K}) / \mathrm{Si}$ & $\mathrm{K} / \mathrm{Na}$ & $\mathrm{Ca} /(\mathrm{Na}+\mathrm{K})$ & {$\left[\mathrm{Na}^{+}+\mathrm{K}^{+}\right]$} \\
\hline No. & i.d. & $\mathrm{g}$ & $\mathrm{g}$ & $\mathrm{g}$ & $\mathrm{g}$ & $\mathrm{mL}$ & $\mathrm{g} / \mathrm{g}$ & & & molar ratio & & $\mathrm{mmol} / \mathrm{L}$ \\
\hline 1 & $\mathrm{SNC}$ & 6.008 & 1.402 & 2.000 & - & 50 & 5.31 & 0.25 & 0.5 & 0 & 0.5 & 1000 \\
2 & $\mathrm{SK}_{0.25} \mathrm{~N}_{0.25} \mathrm{C}$ & 6.008 & 1.402 & 1.000 & 1.403 & 50 & 5.10 & 0.25 & 0.5 & 1.0 & 0.5 & 1000 \\
3 & $\mathrm{SK}_{0.35} \mathrm{~N}_{0.15} \mathrm{C}$ & 6.008 & 1.402 & 0.600 & 1.964 & 50 & 5.01 & 0.25 & 0.5 & 2.3 & 0.5 & 1000 \\
4 & $\mathrm{SK}_{0.43} \mathrm{~N}_{0.07} \mathrm{C}$ & 6.008 & 1.402 & 0.280 & 2.413 & 50 & 4.95 & 0.25 & 0.5 & 6.1 & 0.5 & 1000 \\
5 & SKC or SKC\# & 6.008 & 1.402 & - & 2.805 & 50 & 4.89 & 0.25 & 0.5 & - & 0.5 & 1000 \\
6 & C-S-H_Na & 4.000 & 1.120 & 0.666 & - & 100 & 17.3 & 0.3 & 0.25 & 0 & 1.2 & 170 \\
7 & Na-gel (Silica gel) & 4.000 & - & 1.332 & - & 60 & 11.3 & 0 & 0.5 & 0 & 0 & 560 \\
8 & K-gel (Silica gel) & 4.000 & - & - & 1.868 & 60 & 10.2 & 0 & 0.5 & - & 0 & 330 \\
\hline
\end{tabular}

a $\mathrm{SKC \#}$ is a replicate synthesis of SKC, the difference is that SKC\# was shaken weekly during synthesis, while SKC was not shaken.

Table 2. Mass balance calculated chemical compositions of the solids based on the measured dissolved concentrations in the solutions of the mixtures in equilibrium.

\begin{tabular}{llllll}
\hline & & $\mathrm{Ca} / \mathrm{Si}$ & $\mathrm{Na} / \mathrm{Si}$ & $\mathrm{K} / \mathrm{Si}$ & total $\mathrm{H}_{2} \mathrm{O} / \mathrm{Si}$ at $35 \% \mathrm{RH}$ \\
\cline { 3 - 5 } & & solid & solid & Solid & $\mathrm{mol} / \mathrm{mol}$ \\
\hline 1 & $\mathrm{SNC}$ & 0.29 & 0.35 & - & 0.95 \\
2 & $\mathrm{SK}_{0.25} \mathrm{~N}_{0.25} \mathrm{C}$ & 0.32 & 0.15 & 0.23 & 0.73 \\
3 & $\mathrm{SK}_{0.35} \mathrm{~N}_{0.15} \mathrm{C}$ & 0.32 & 0.10 & 0.29 & - \\
4 & $\mathrm{SK}_{0.43} \mathrm{~N}_{0.07} \mathrm{C}$ & 0.32 & 0.05 & 0.34 & 0.63 \\
5 & $\mathrm{SKC}$ & 0.30 & - & 0.41 & $0.78 \pm 0.08$ for SKC\# (0.87 from [32]) \\
6 & $\mathrm{C}-\mathrm{S}-\mathrm{H} \_\mathrm{Na}$ & 0.35 & 0.15 & - & - \\
7 & Na-gel (Silica gel) & - & 0.06 & - & - \\
8 & K-gel (Silica gel) & - & - & 0.28 & - \\
\hline
\end{tabular}


Table 3. Peak assignments of Raman bands from published studies.

\begin{tabular}{|c|c|c|}
\hline $\begin{array}{l}\text { Raman } \\
\text { Frequency } \\
\left(\mathrm{cm}^{-1}\right)\end{array}$ & Assignment & References \\
\hline $200-350$ & Vibrations involving $\mathrm{Ca}-\mathrm{O}$ polyhedra & {$[36][38][41][37]$} \\
\hline $400-500$ & $\begin{array}{l}\text { Internal deformations of } \mathrm{Si}-\mathrm{O} \text { tetrahedra, O-Si-O } \\
\text { bending, } \mathrm{Q}^{4}\end{array}$ & {$[36][38][41]$} \\
\hline 600 & $\begin{array}{l}\text { Symmetrical bending (SB) involving } \mathrm{Q}^{3} \quad \mathrm{Si} \\
\text { tetrahedra }\end{array}$ & {$[36][38]$} \\
\hline 638 & $\mathrm{SB}$ of Si-O-Si linkages for $\mathrm{Q}^{2}$ or $\mathrm{Q}^{3}$ groups & [36], this study \\
\hline 670 & $\mathrm{SB}$ of Si-O-Si linkages in $\mathrm{Q}^{2}$ or $\mathrm{Q}^{3}$ groups & $\begin{array}{l}{[36][38][41] \text {, this }} \\
\text { study }\end{array}$ \\
\hline 880 & Symmetrical stretching (SS) of $\mathrm{Q}^{1}$ tetrahedra & [36] [38] \\
\hline 1010 & $\mathrm{SS}$ of $\mathrm{Q}^{2}$ tetrahedra & [36] [38] \\
\hline 1020 & $\mathrm{SS}$ of $\mathrm{Q}^{2}$ tetrahedra & [36] [38] \\
\hline 1065 & $\mathrm{SS}$ of $\mathrm{Q}^{3}$ tetrahedra & {$[36][38][40]$} \\
\hline 1078 & Symmetrical C-O stretching in carbonate groups & [38] \\
\hline 1086 & $\mathrm{SS}$ of $\mathrm{Q}^{3}$ tetrahedra & {$[36][40]$} \\
\hline 1115 & $\begin{array}{l}\text { Symmetrical stretching (SS) of } \mathrm{Si}-\mathrm{O} \text { tetrahedra in } \\
\mathrm{Q}^{3} \text { groups }\end{array}$ & {$[36][53]$} \\
\hline
\end{tabular}

Table 4. Summary of the main characteristic peaks of Raman and FTIR spectra of the studied samples

\begin{tabular}{llll}
\hline $\begin{array}{l}\text { Raman Frequency } \\
\left(\mathrm{cm}^{-1}\right)\end{array}$ & Corresponding phases & $\begin{array}{l}\text { FTIR Frequency } \\
\left(\mathrm{cm}^{-1}\right)\end{array}$ & Corresponding phases \\
\hline 607 & Na-shlykovite $\left(\mathrm{Q}^{3}\right)$ & 629 & ASR-P1 \\
595 & K-shlykovite $\left(\mathrm{Q}^{3}\right)$ & 652 & ASR-P1 \\
639 & ASR-P1 $\left(\mathrm{Q}^{3}\right)$ & 688 & Na-shlykovite \\
675 & ASR-P1 $\left(\mathrm{Q}^{3}\right)$ & 931 & C-S-H \\
668 & C-S-H $\left(\mathrm{Q}^{2}\right)$ & 958 & K-shlykovite \\
1007 & C-S-H $\left(\mathrm{Q}^{2}\right)$ & 967 & Na-shlykovite \\
1063 & ASR-P1 $\left(\mathrm{Q}^{3}\right)$ & 969 & C-S-H \\
1087 & Na/K-shlykovite $\left(\mathrm{Q}^{3}\right)$ & 990 & Na-shlykovite \\
1120 & ASR-P1 $\left(\mathrm{Q}^{3}\right)$ & 1023 & Na/K-shlykovite \\
\hline
\end{tabular}


Table 5. Measured dissolved concentrations in the solutions of the mixtures in equilibrium and calculated saturated indices.

\begin{tabular}{|c|c|c|c|c|c|c|c|c|c|}
\hline & & \multirow{2}{*}{$\frac{\mathrm{Si}}{\mathrm{mM}}$} & \multirow{2}{*}{$\frac{\mathrm{Na}}{\mathrm{mM}}$} & \multirow{2}{*}{$\frac{\mathrm{K}}{\mathrm{mM}}$} & \multirow{2}{*}{$\frac{\mathrm{Ca}}{\mathrm{mM}}$} & \multirow{2}{*}{$\frac{\mathrm{OH}^{-}}{\mathrm{mM}}$} & \multirow{2}{*}{$\begin{array}{l}\mathrm{pH}_{\mathrm{cal}} \\
\left(23^{\circ} \mathrm{C}\right)\end{array}$} & \multicolumn{2}{|c|}{ Saturation indices } \\
\hline & & & & & & & & $\mathrm{SiO}_{2}$ & C-S-H \\
\hline 1 & SNC & 302 & 402 & - & 0.025 & 48.5 & 12.64 & -2.1 & -0.9 \\
\hline 2 & $\mathrm{SK}_{0.25} \mathrm{~N}_{0.25} \mathrm{C}$ & 442 & 269 & 135 & 0.026 & 7.85 & 11.92 & -1.3 & -0.9 \\
\hline 3 & $\mathrm{SK}_{0.35} \mathrm{~N}_{0.15} \mathrm{C}$ & 450 & 146 & 243 & 0.029 & 7.53 & 11.90 & -1.3 & -0.9 \\
\hline 4 & $\mathrm{SK}_{0.43} \mathrm{~N}_{0.07} \mathrm{C}$ & 417 & 57.5 & 317 & 0.018 & 10.7 & 11.99 & -1.4 & -1.0 \\
\hline 5 & $\mathrm{SKC}$ & 315 & - & 303 & 0.012 & 14.3 & 12.12 & -1.5 & -1.1 \\
\hline 6 & C-S-H_Na & 99.2 & 82.0 & - & 0.321 & 1.48 & 11.17 & -0.6 & -0.4 \\
\hline 7 & Na-gel (Silica gel) & 904 & 543 & - & $0.036^{\mathrm{a}}$ & 1.66 & 11.19 & -0.2 & -4.7 \\
\hline 8 & K-gel (Silica gel) & 902 & - & 496 & $0.025^{\mathrm{a}}$ & 2.2 & 11.30 & -0.4 & -4.6 \\
\hline
\end{tabular}

a The trace of $\mathrm{Ca}$ measured for these two samples is attributed to the impurity of the raw materials. Similar amount of Ca measured for samples 1-5 suggests that all the freshly burnt $\mathrm{CaO}$ introduced in the beginning has reacted to form solid phases. 

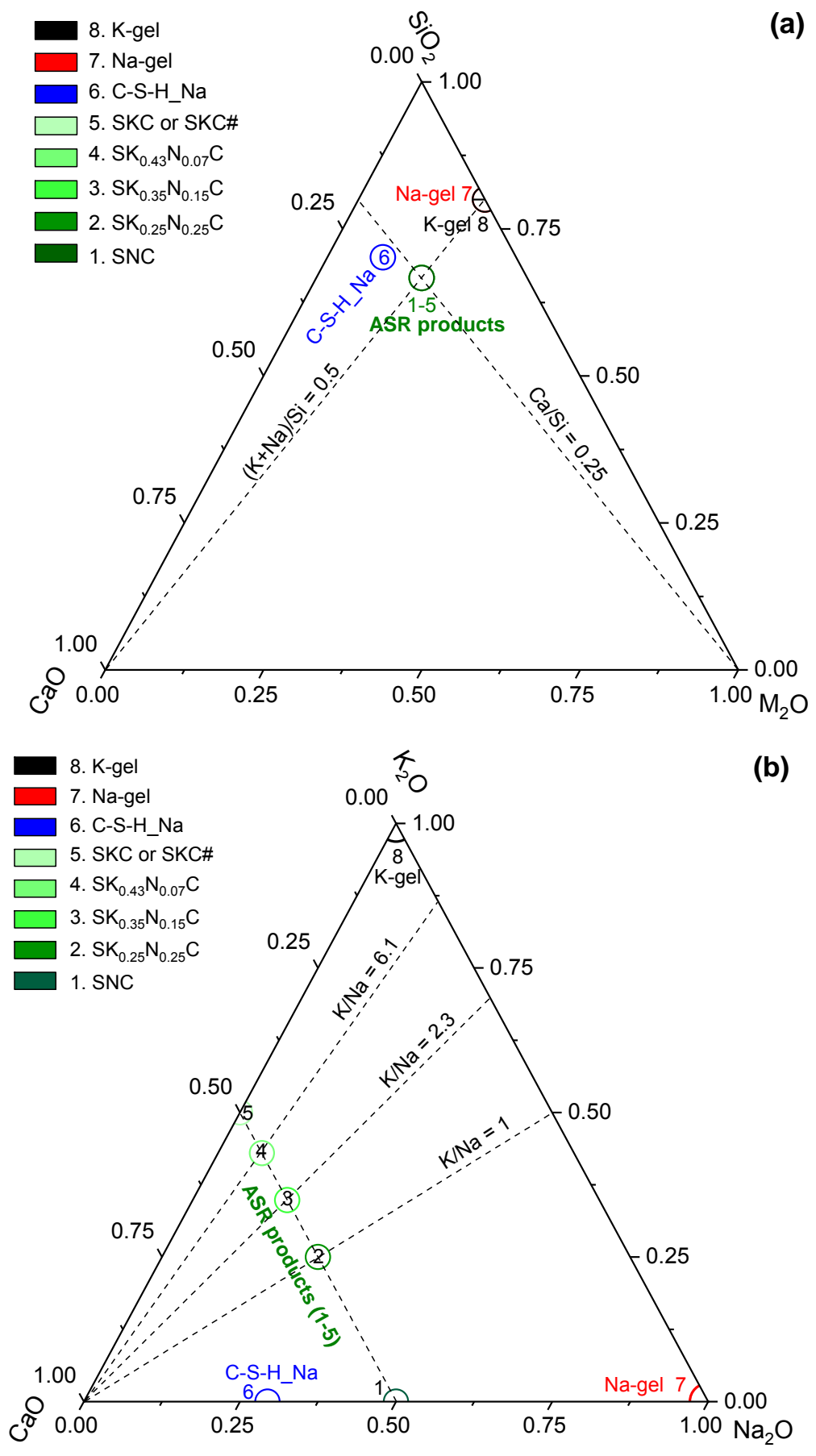

Fig. 1. Bulk chemical compositions of the starting materials (empty circle) with the chemical composition of each sample projected in both (a) $\mathrm{CaO}-\mathrm{SiO}_{2}-\mathrm{M}_{2} \mathrm{O}$ and (b) $\mathrm{CaO}-\mathrm{K}_{2} \mathrm{O}-\mathrm{Na}_{2} \mathrm{O}$ ternary diagrams. 


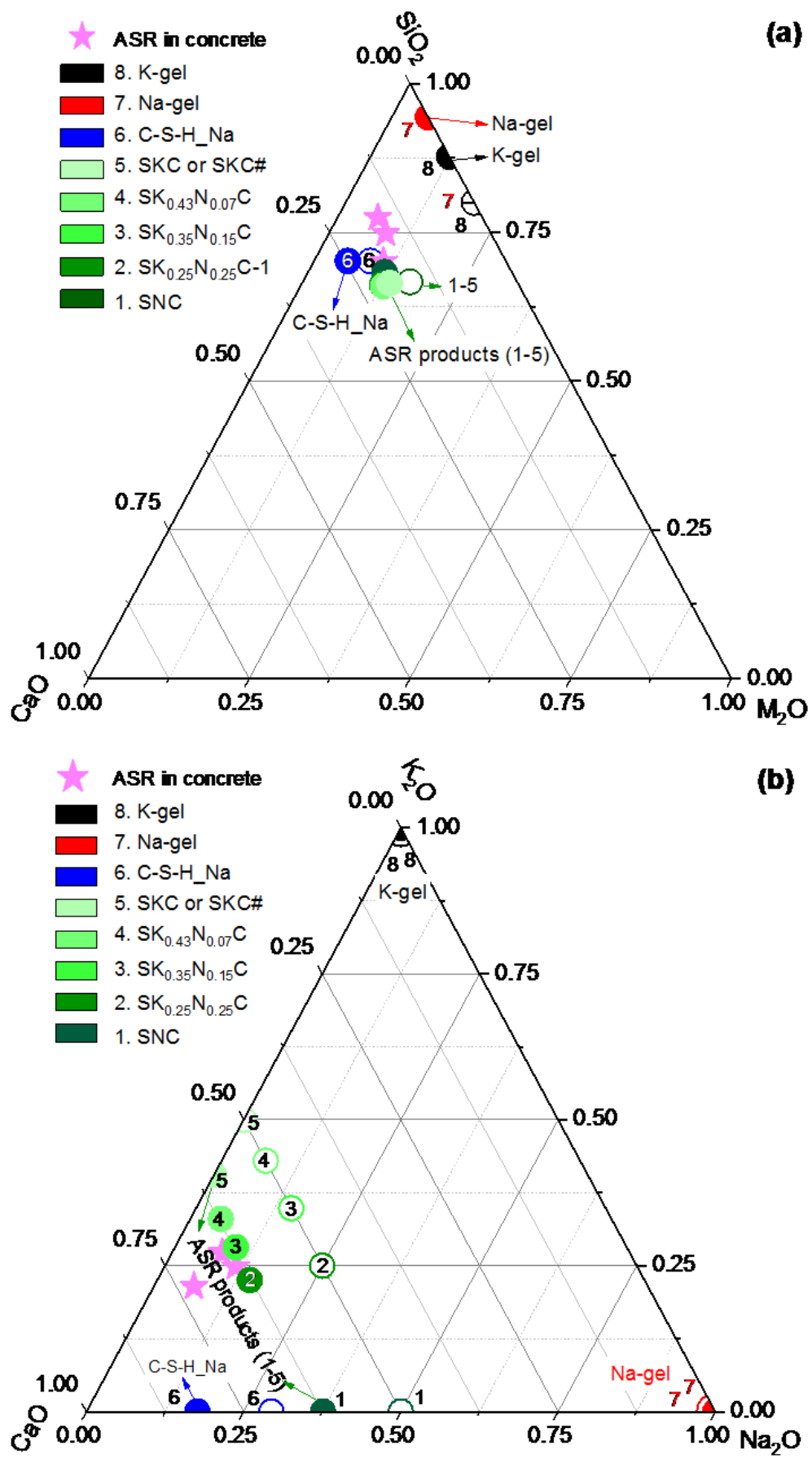

Fig. 2. Bulk chemical compositions of the starting materials (empty circle) and the solids obtained after 80 days of reaction at $80{ }^{\circ} \mathrm{C}$ (filled circle). The same chemical composition of each sample is projected in (a) $\mathrm{CaO}-\mathrm{SiO}_{2}-\mathrm{M}_{2} \mathrm{O}$ and (b) $\mathrm{CaO}-\mathrm{K}_{2} \mathrm{O}-\mathrm{Na}_{2} \mathrm{O}$ and ternary diagrams. The three star symbol correspond to the chemical composition of the ASR products from concrete structure [10]. 


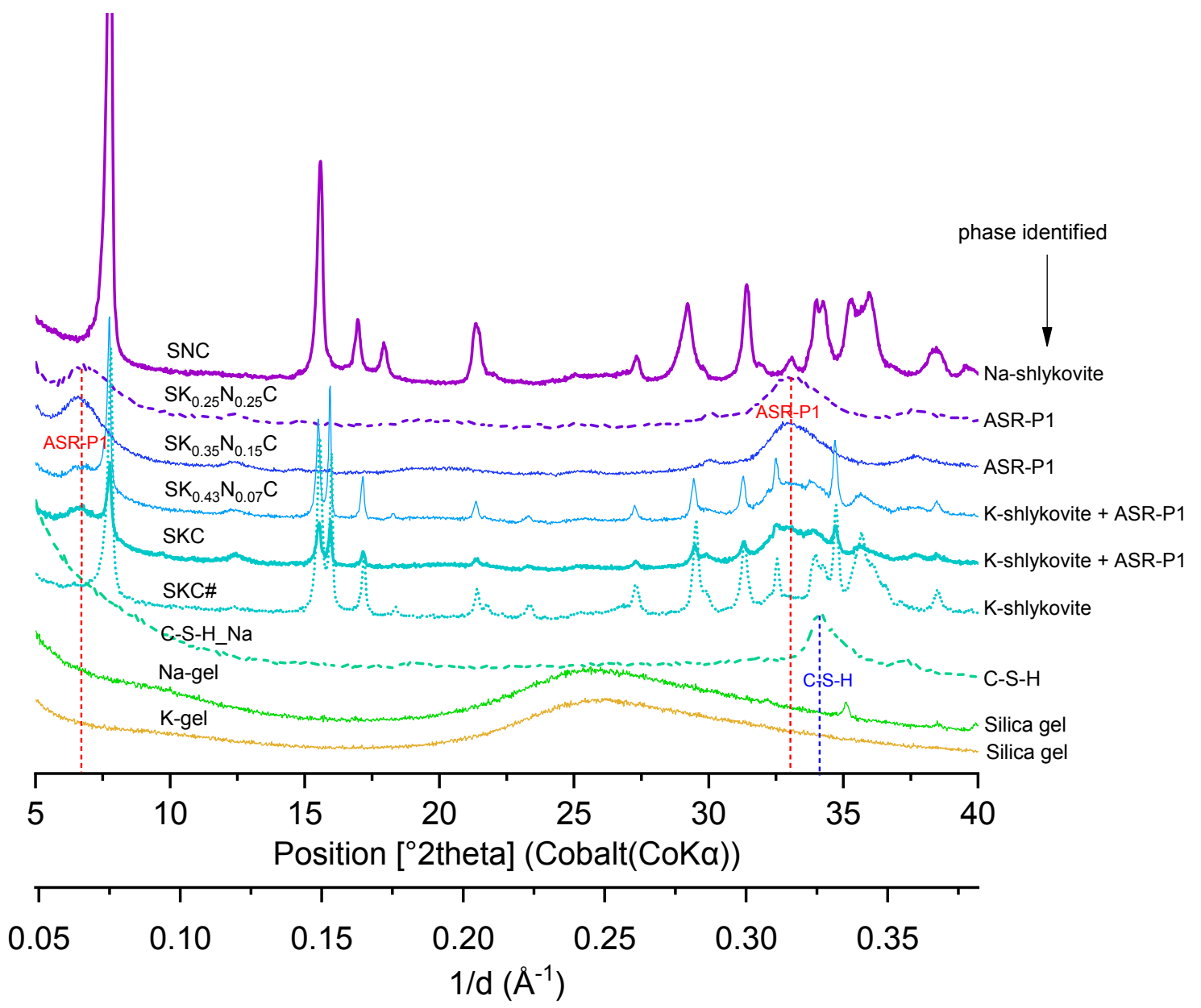

Fig. 3. XRD diffractograms of the solids obtained after 80 days of reaction at $80{ }^{\circ} \mathrm{C}$. C-S-H: calcium-silicate-hydrate; ASR-P1: an new phase; K-gel and Na-gel: silica gels in the absence of $\mathrm{Ca}$. 
(a)

(a)

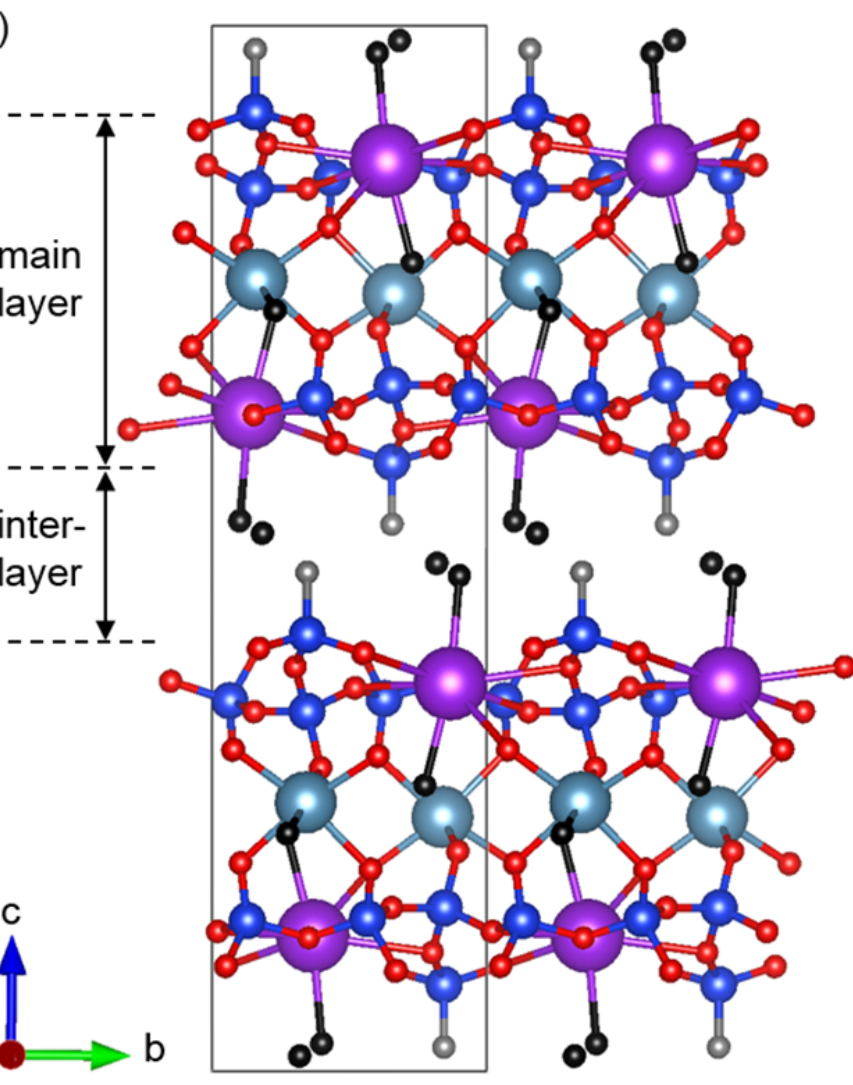

(b)

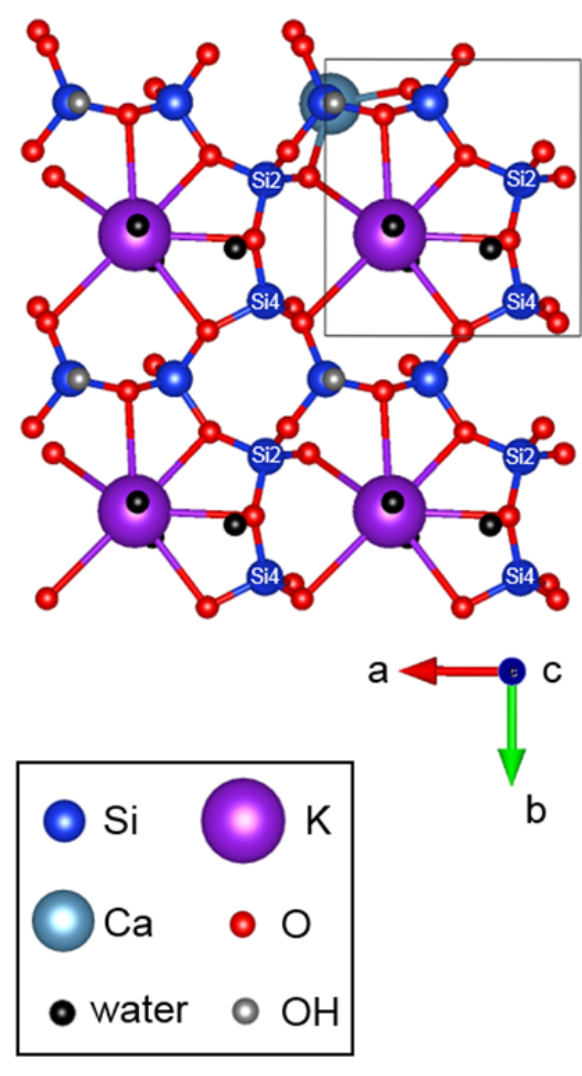

Fig. 4. A schematic structure of shlykovite from literature [33], (a) viewed along [100], (b) the potassium silicate layer viewed along [001]. 
(a)

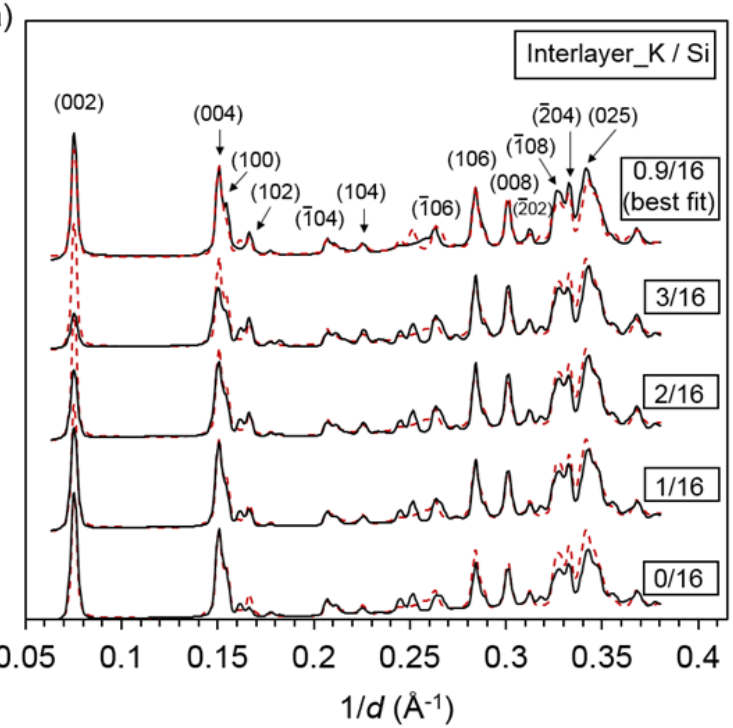

(b)

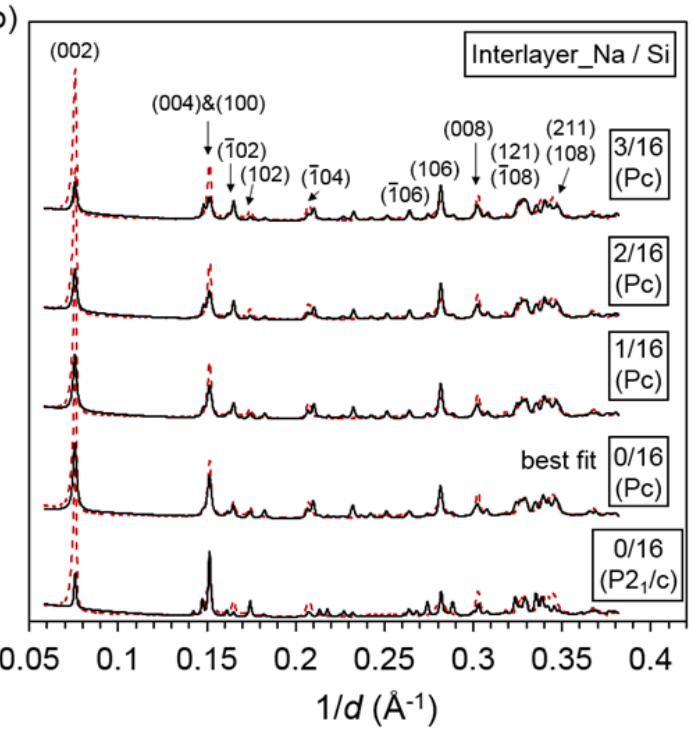

Fig. 5. The XRD patterns of (a) SKC\# measured with synchrotron X-ray and (b) SNC measured with conventional X-ray, which are refined with modified shlykovite structures that have various $\mathrm{K}$ or $\mathrm{Na}$ content in the interlayer. Experimental data is plotted in red dashed line together with each fitting result plotted in black solid line to ease comparison. 


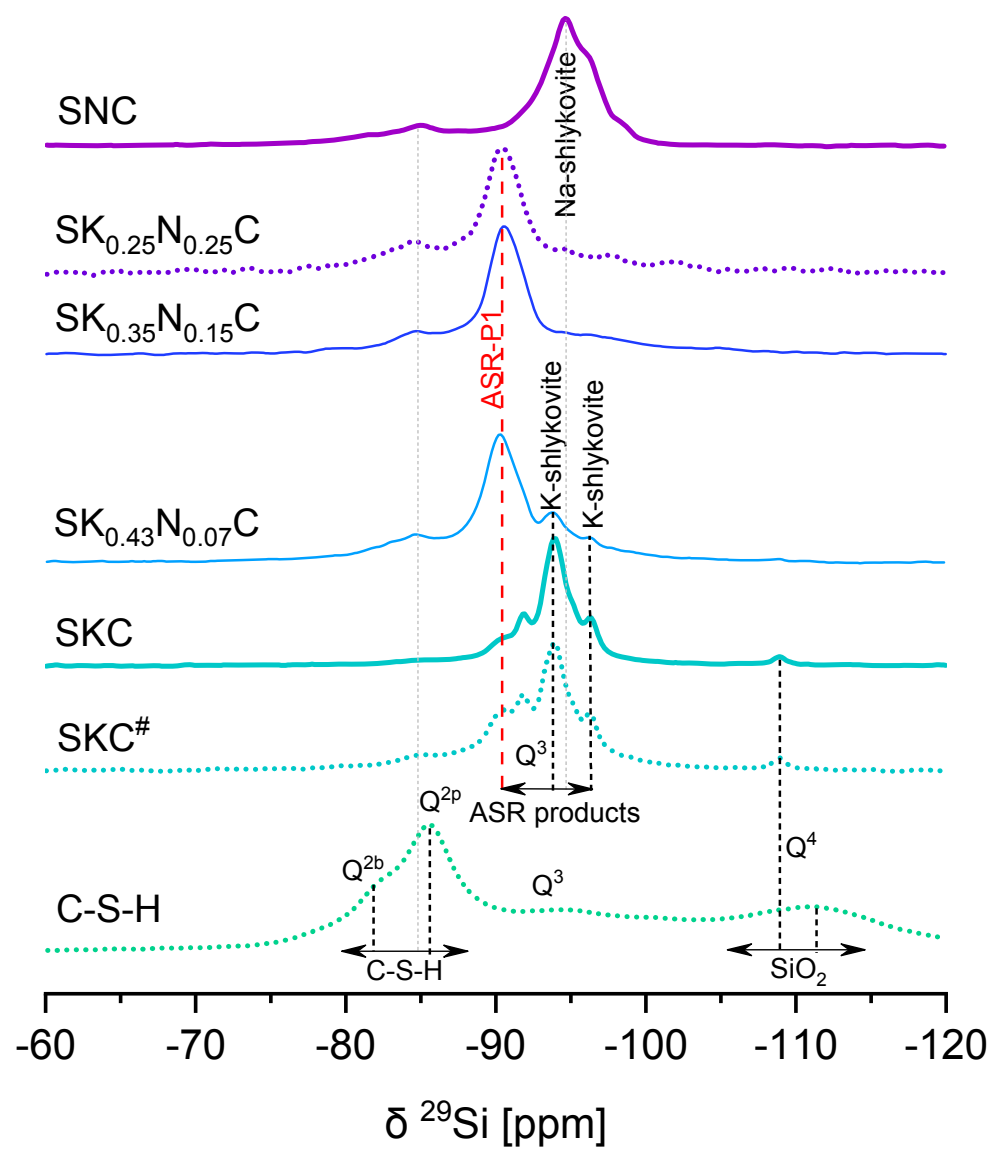

Fig. $6 .{ }^{29} \mathrm{Si}$ MAS NMR spectra of the solids obtained after 80 days of reaction at $80{ }^{\circ} \mathrm{C}$. 


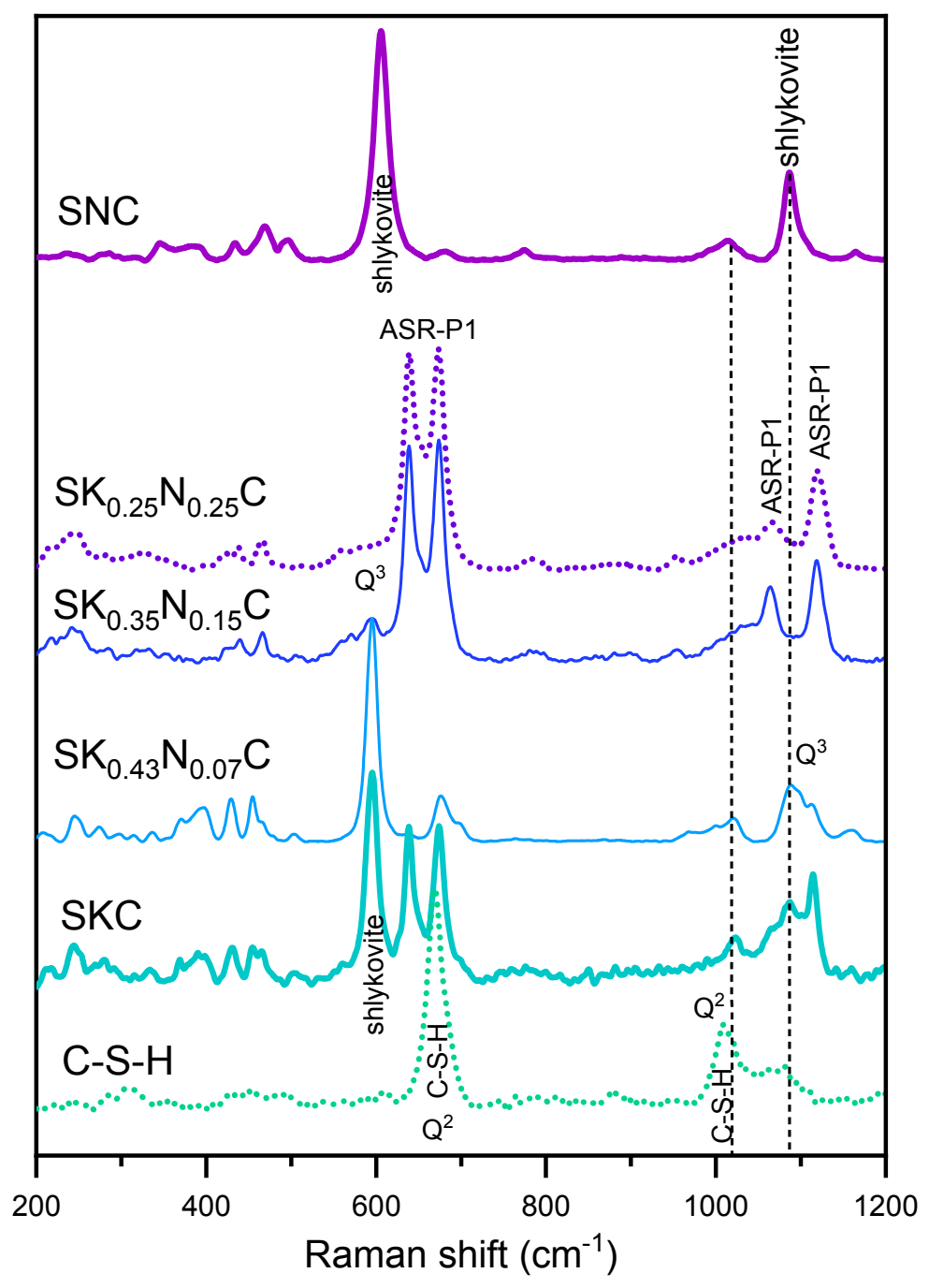

Fig. 7. Raman spectra of the solids obtained after 80 days of reaction at $80{ }^{\circ} \mathrm{C}$. 

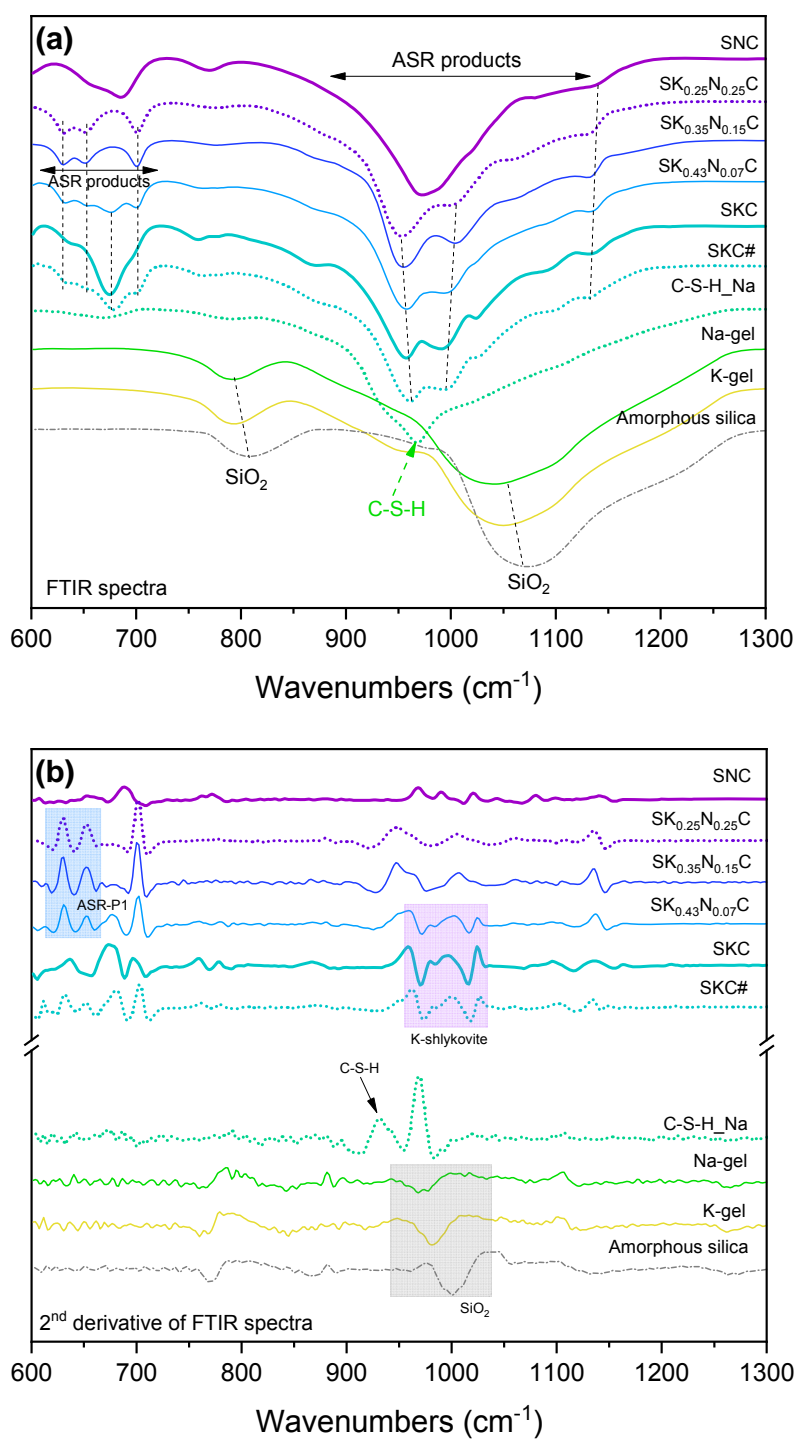

Fig. 8. (a) FTIR spectra and (b) second derivative of FTIR of the solids obtained after 80 days of reaction at $80^{\circ} \mathrm{C}$. 


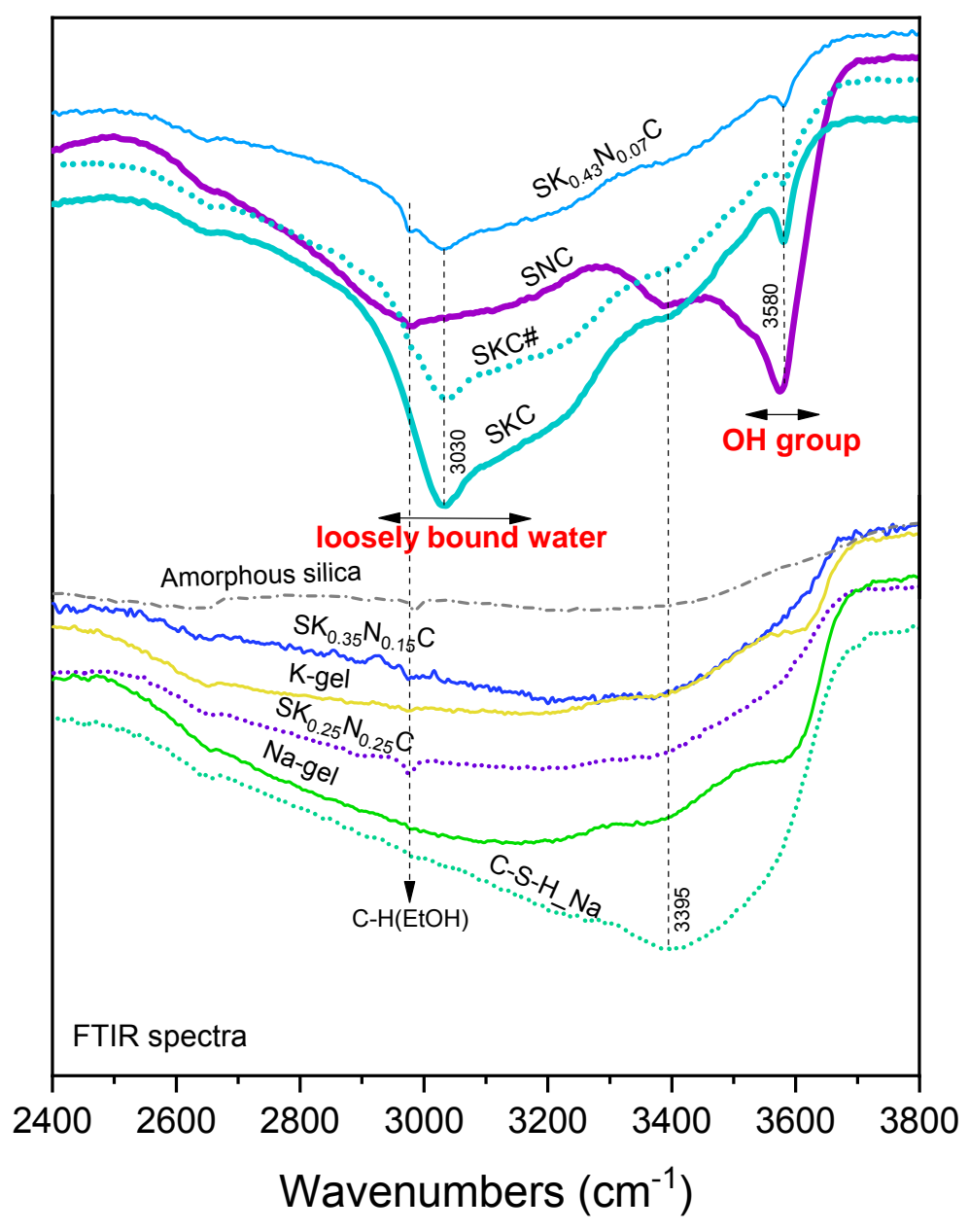

Fig. 9. FTIR spectra in the range with respect to stretching vibrations of $\mathrm{O}-\mathrm{H}$ groups in $\mathrm{H}_{2} \mathrm{O}$ or hydroxyls with a wide range of hydrogen-bond strengths. 


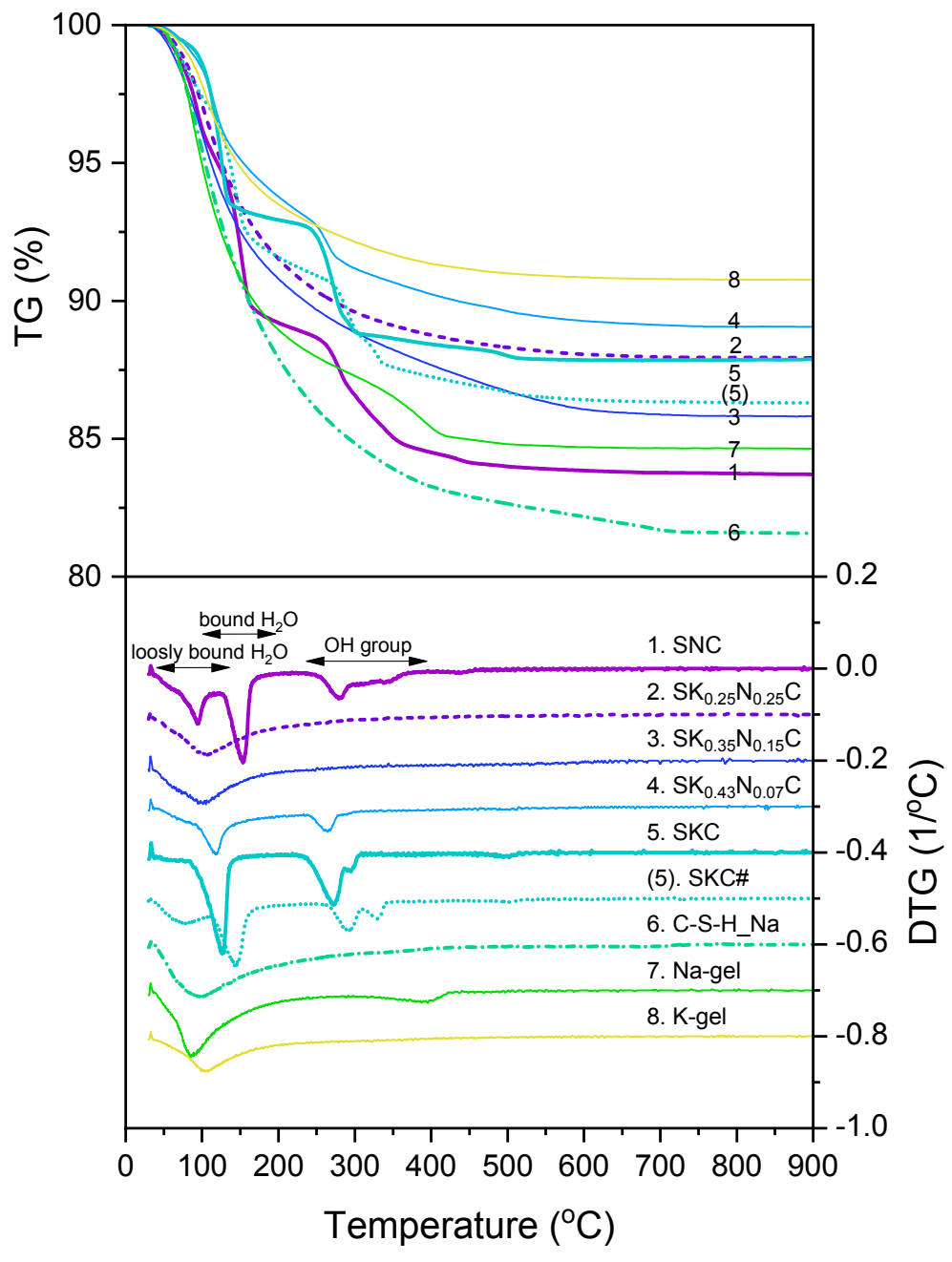

Fig. 10. DTG curves of the solids obtained after 80 days of reaction at $80{ }^{\circ} \mathrm{C}$. 


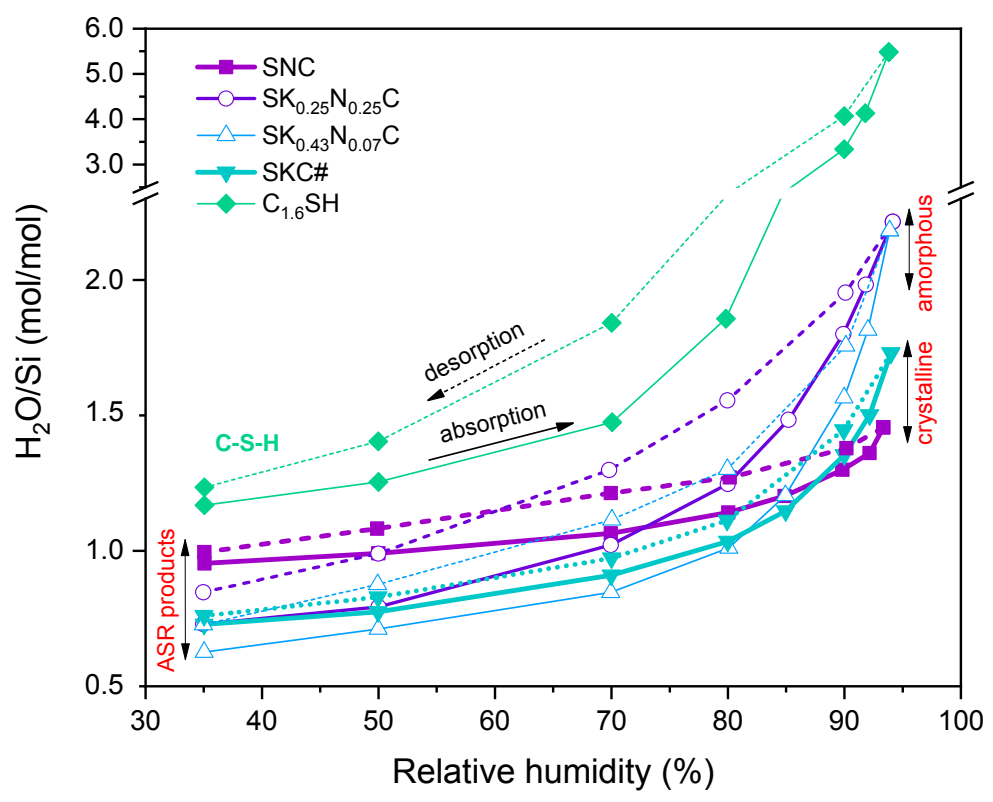

Fig. 11. Dynamic vapor sorption results for different synthetic ASR products and C-S-H phase. Crystalline phases: Na-shlykovite in SNC; K-shlykovite in SKC\# and $\mathrm{SK}_{0.43} \mathrm{~N}_{0.07} \mathrm{C}$. Amorphous phase: ASR-P1 phase in $\mathrm{SK}_{0.25} \mathrm{~N}_{0.25} \mathrm{C}$ and $\mathrm{SK}_{0.43} \mathrm{~N}_{0.07} \mathrm{C}$. 


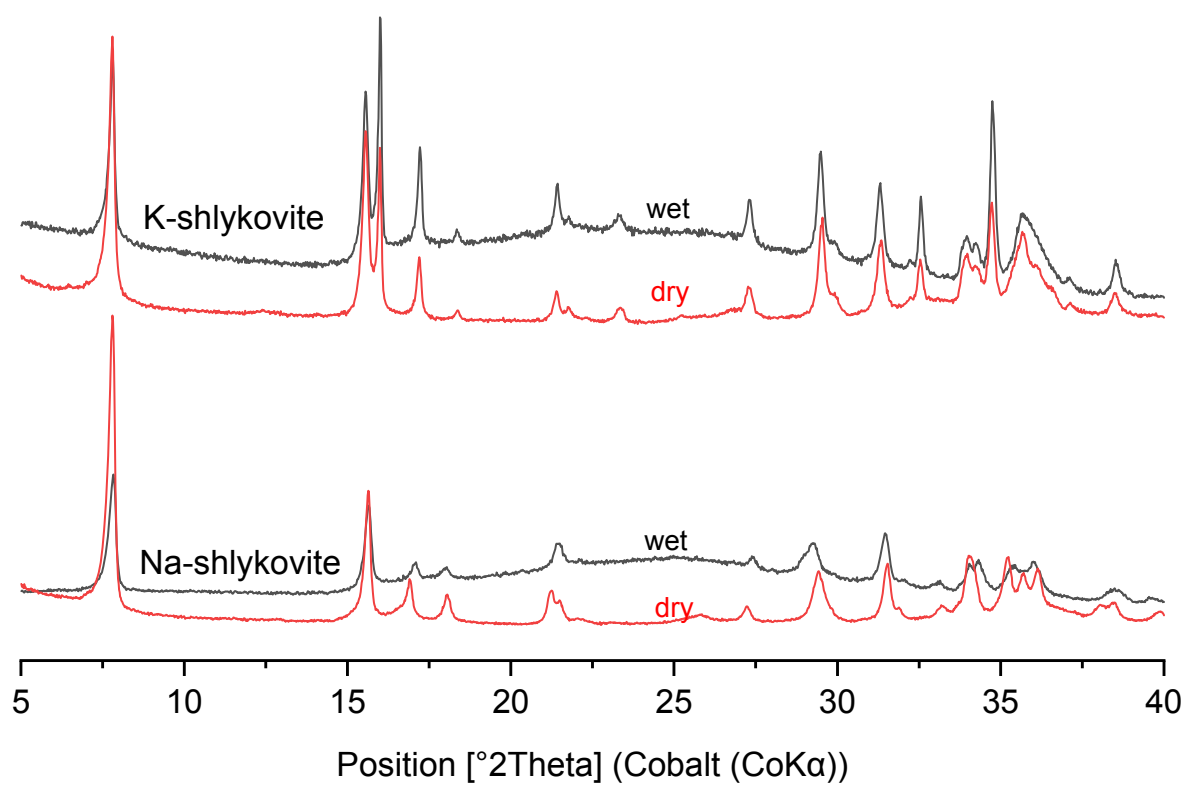

Fig. 12. Effect of wet and drying conditions on the basal d-spacing of the K-shlykovite formed in sample SKC\# and Na-shlykovite formed in sample SNC. 

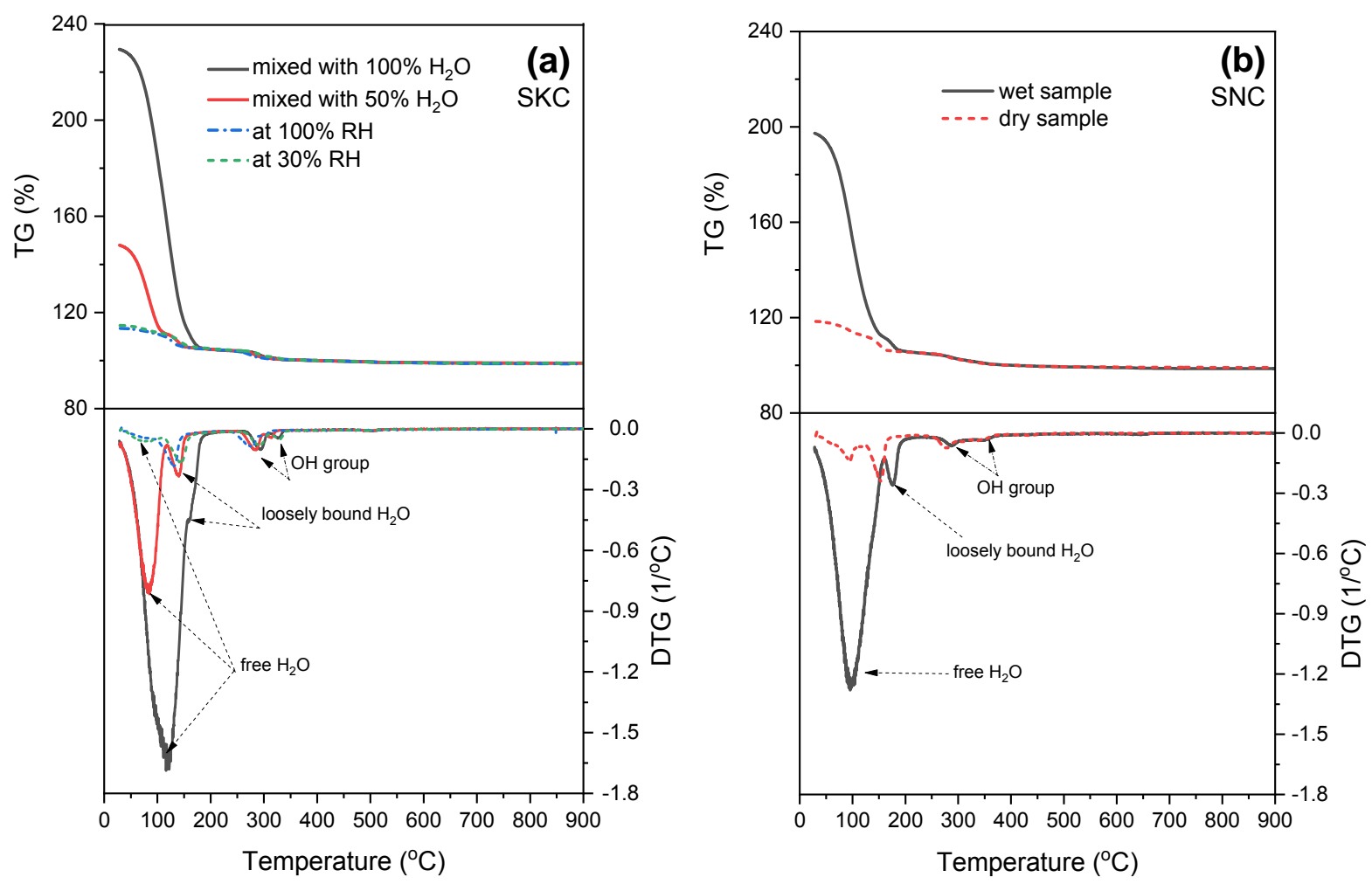

Fig. 13. Effect of drying conditions of (a) SKC sample and (b) SNC sample on the loosely bound $\mathrm{H}_{2} \mathrm{O}$ and $\mathrm{OH}$ group in $\mathrm{K}$-shlykovite and Na-shlykovite, respectively. The relative weight losses of the samples at different drying conditions are normalized by their relative weights at $400{ }^{\circ} \mathrm{C}$. 


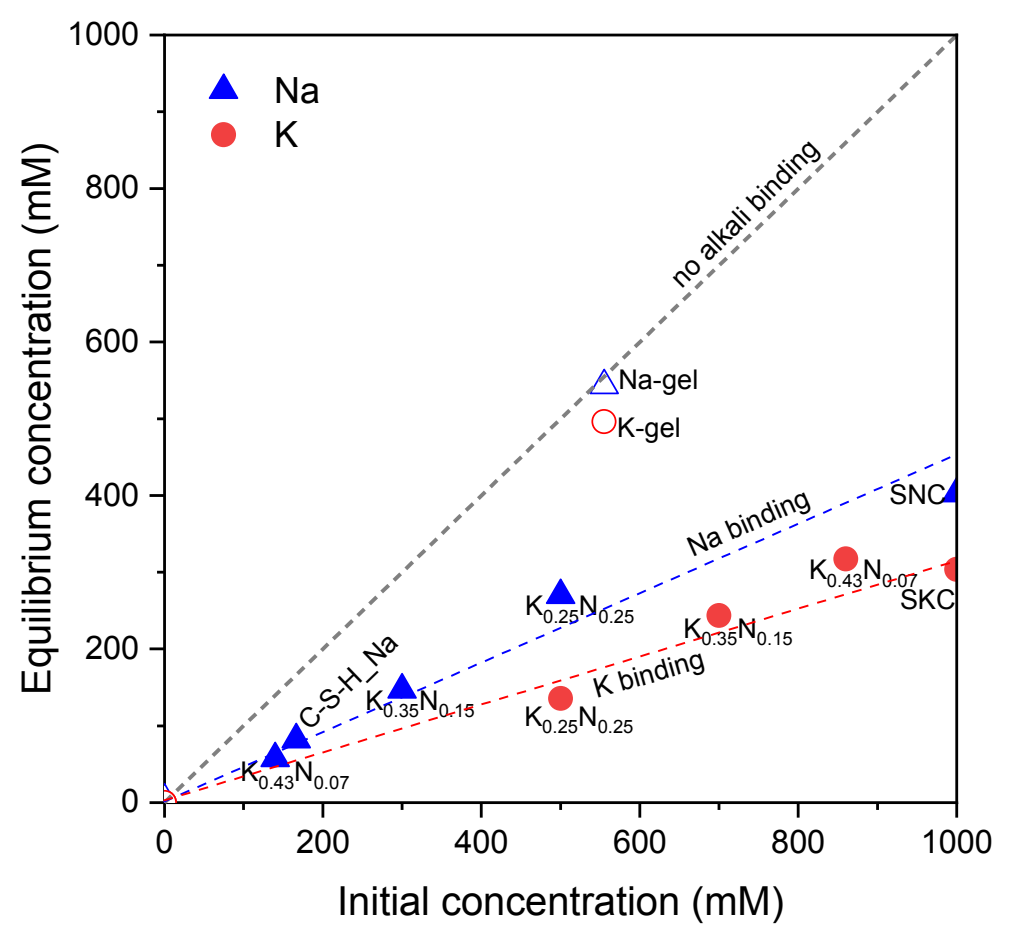

Fig. 14. Relationships between the equilibrium and initial concentration of $\mathrm{Na}$ and $\mathrm{K}$ in the solutions of different mixtures. 

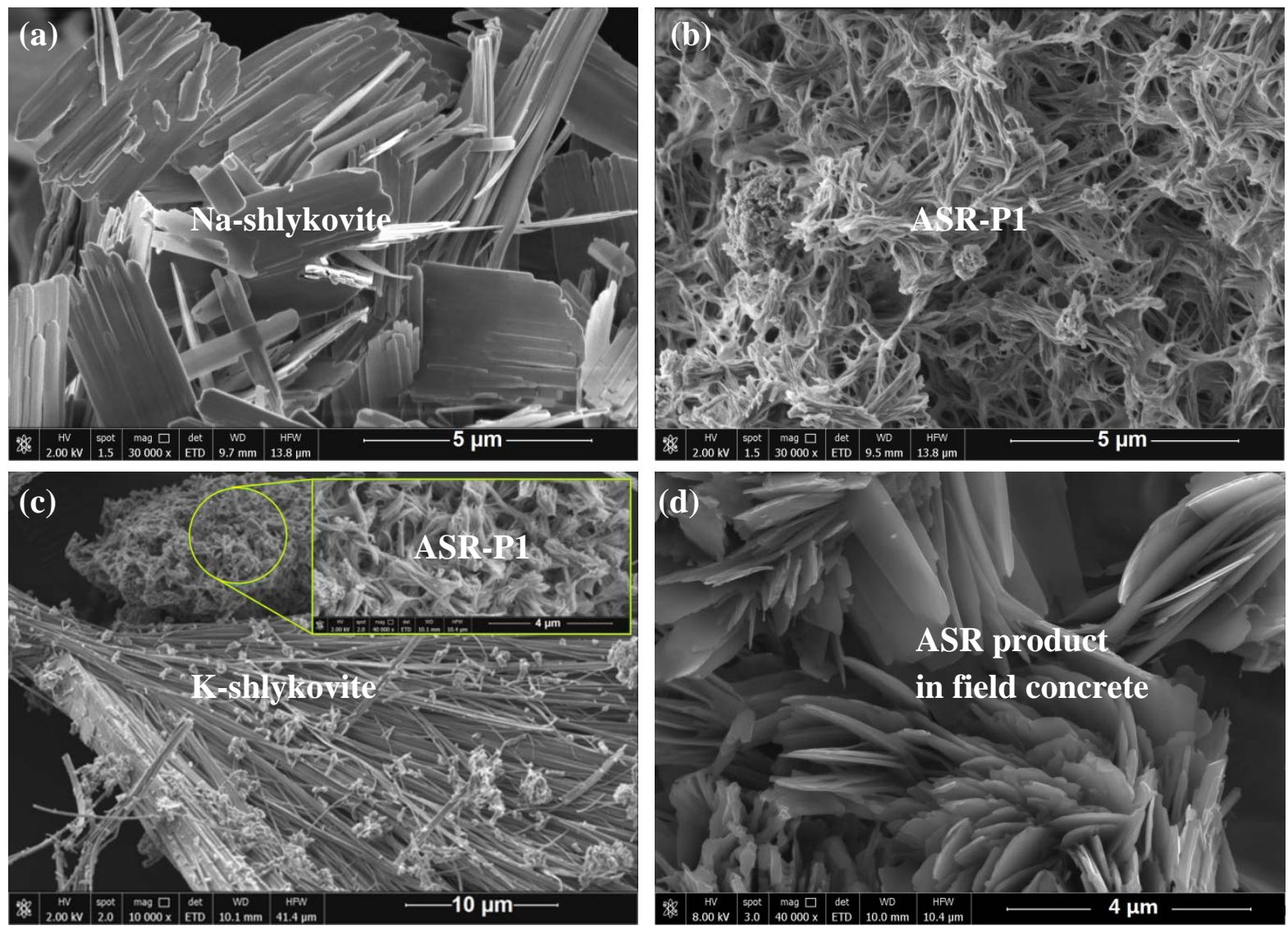

Fig. 15. SEM morphologies of (a) plate-like Na-shlykovite formed in the sample SNC, (b) nanocrystalline ASR-P1 phase formed in the sample $\mathrm{SK}_{0.25} \mathrm{~N}_{0.25} \mathrm{C}$, (c) fiber-like K-shlykovite and nanocrystalline ASR-P1 phase formed in the sample $\mathrm{SK}_{0.43} \mathrm{~N}_{0.07} \mathrm{C}$, and (d) plate-like ASR product formed in the concrete from a 40 year old bridge in Mels, Switzerland . 


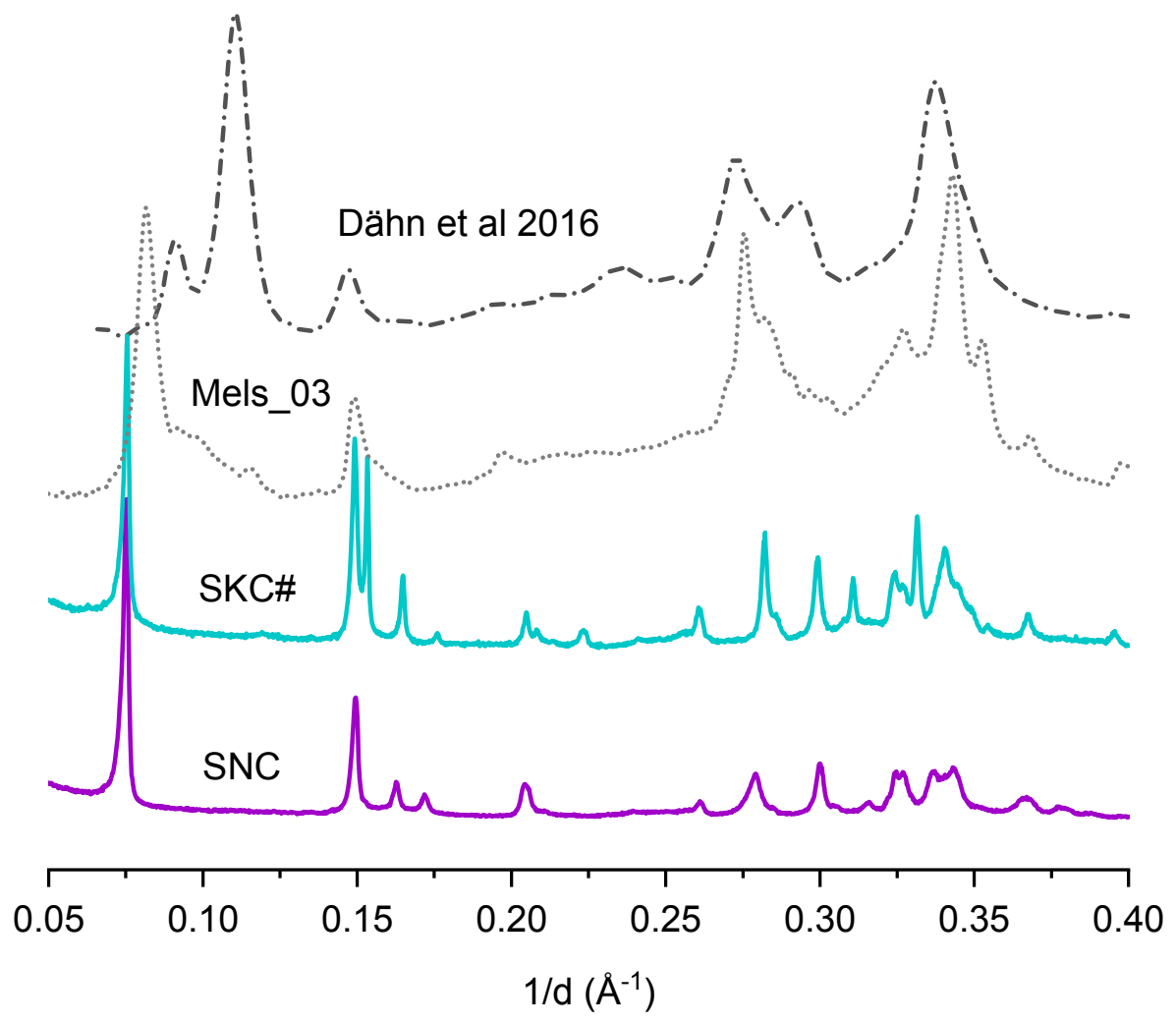

Fig. 16. Comparison of XRD patterns of the K-shlykovite and Na-shlykovite formed in the SKC\# and SNC samples respectively with XRD pattern obtained by synchrotron-based micro- X-ray diffraction (micro-XRD) for the ASR product formed in aggregate of a 40 year old bridge in Mels, Switzerland [19] and for ASR product formed in an air void of a concrete from the same bridge (labeled as Mels_03). 


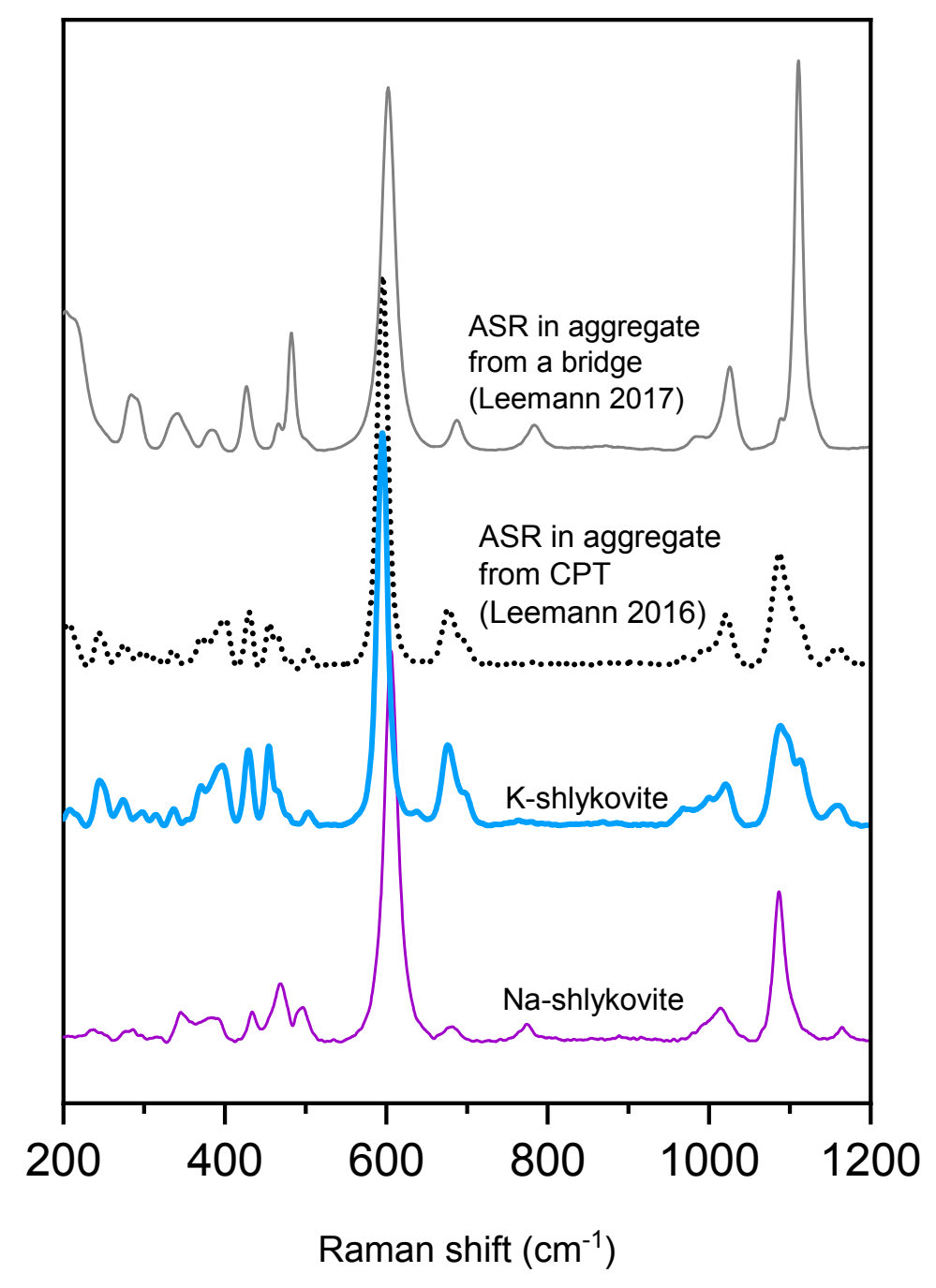

Fig. 17. Comparison of the Raman spectra of K-shlykovite (i.e., crystalline part of the sample $\mathrm{SK}_{0.43} \mathrm{~N}_{0.07} \mathrm{C}$ ), Na-shlykovite (i.e., SNC) synthesized at $80{ }^{\circ} \mathrm{C}$, the crystalline ASR product formed in aggregate from concrete prism test (CPT), where the sample had been subjected to $60{ }^{\circ} \mathrm{C}$ for 20 weeks [52], and the ASR product formed in aggregate from a 40 year old bridge in Mels, Switzerland [20]. 